\title{
Study on Surface Quality and Corrosion Resistance of Ultrasonic Vibration Assisted Micromilling Inconel718
}

\section{Zhonghang Yuan}

Hefei University of Technology

\section{Bin Fang}

Shandong Institute of Mechanical Design and Research

\section{Yude Dong ( $\nabla$ yddong@hfut.edu.cn )}

Hefei University of Technology

Heng Ding

Hefei University of Technology

\section{Yuanbin Zhang}

Shandong Institute of Mechanical Design and Research

\section{Research Article}

Keywords: Ultrasonic vibration assisted micromilling, Micromilling, Cutting force, Tool wear, Surface quality, Corrosion resistance

Posted Date: December 29th, 2021

DOI: https://doi.org/10.21203/rs.3.rs-1188990/v1

License: (c) (i) This work is licensed under a Creative Commons Attribution 4.0 International License. Read Full License 


\title{
Study on surface quality and corrosion resistance of
}

\section{ultrasonic vibration assisted micromilling Inconel718}

\author{
Zhonghang Yuan ${ }^{1}$, Bin Fang ${ }^{2,3}$, Yude Dong ${ }^{1}{ }^{*}$, Heng Ding ${ }^{1}$, Yuanbin \\ Zhang ${ }^{2,3}$ \\ ${ }^{1}$ School of Mechanical Engineering, Hefei University of Technology, Hefei \\ 230009, China; ${ }^{2}$ School of Mechanical and Automotive Engineering, Qilu \\ University of Technology (Shandong Academy of Sciences), Jinan, Shandong, \\ 250353, China; ${ }^{3}$ Shandong Institute of Mechanical Design and Research, Jinan, \\ Shandong, 250353, China
}

\begin{abstract}
Micromilling (MM) is favored by the field of high-precision micro parts. However, the high plasticity of Inconel718 often poses a threat to MM, such as pits, humps and gullies, which affect the surface quality. In this study, the influence of ultrasonic vibration assisted micromilling (UVAMM) on surface quality is comprehensively analyzed by using the machining process of workpiece vibration, combined with cutting force, tool wear, surface morphology and corrosion resistance. The results show that, on the one hand, small amplitude plays a significant role in reducing cutting force and inhibiting tool wear. On the other hand, smaller speed, smaller feed rate and moderate amplitude will produce better surface morphology, which is a uniform and regular fish scale surface with lower surface roughness and fewer surface defects. Furthermore, the application of ultrasonic vibration also significantly improves the surface corrosion resistance of Inconel718. It is worth noting that the surface corrosion resistance does not completely depend on the surface roughness, but also has a close correlation with the surface morphology.
\end{abstract}

Keywords: Ultrasonic vibration assisted micromilling; Micromilling; Cutting force; Tool wear; Surface qu ality; Corrosion resistance

*Corresponding author. E-mail address: yddong@hfut.edu.cn

\section{Introduction}

In recent years, with the rapid development of aerospace, medical devices and oceanographic engineering, high-precision micro parts are required to have higher assembly accuracy and better surface properties [1,2]. Inconel718 alloy has more excellent high temperature strength, plasticity and toughness, so it is more widely used [3]. As a high-precision machining method, micromilling (MM) is widely used in the machining of 718 Alloy. However, the machining process is easy to be affected by material plasticity and size effect, resulting in poor surface quality. The surface quality of MM still faces great challenges.

In order to improve the surface quality in the MM process, Wang et al. [4] established a reliable surface roughness prediction model and found that reducing the spindle speed $(n)$ and improving the stability of the machining system are more reasonable means to improve the surface quality. Lu et al. [5] reasonably optimized the parameters of MM through experiments and obtained the optimal surface quality. Mian et al. [6] found through experiments that cutting speed is the main factor to improve 
surface integrity. Moreover, some scholars have studied the effects of different environmental conditions on the cutting process. Oliveira et al. [7] found that the application of high flow cutting fluid can effectively prevent the material from adhering to the machined surface, so as to improve the surface integrity. Ucun et al. [8] studied the effects of micro-lubrication and low-temperature precooling on the cutting performance of MM Inconel718 alloy. Micro-lubrication can effectively reduce tool wear, and low-temperature precooling can effectively improve surface quality. However, the above environmental conditions will cause unnecessary environmental pollution and waste of resources. Therefore, other means need to be found to solve the processing problem of Inconel718. On the other hand, Inconel718 is often used in petrochemical and other fields, so the corrosion resistance of Inconel718 in many weak acidic environments still needs to be solved. At present, the research on the surface corrosion resistance of Inconel718 mainly focuses on the research on the lapping surface, and there is little research on the corrosion resistance of the machined surface. Evgeny et al. [9] studied the relationship between the roughness and corrosion resistance of low carbon steel in hydrochloric acid solution, and found that the greater the roughness, the worse the corrosion resistance. However, Alvarez et al. [10] studied the corrosion effect of $\mathrm{NaCl}$ on magnesium alloy $\mathrm{AE} 44$ and found that when the surface roughness is higher, the corrosion resistance is stronger, which means that the surface roughness can not completely determine the corrosion resistance of the material, and the surface texture also plays a crucial role. Uddin et al. [11] carried out the experiment of milling magnesium alloy AZ31 and improved the microhardness of the milling surface through parameter optimization. It was found that the higher the hardness is, the stronger the corrosion resistance of magnesium alloy is.

Vibration cutting is a kind of machining method to realize periodic high-frequency separation between tool and workpiece by applying high-frequency vibration to tool or workpiece. After decades of research, vibration cutting is widely used in turning, milling and drilling. It has excellent performance in reducing cutting force and cutting temperature [12-15], inhibiting tool wear [16,17], improving surface quality [18,19] and improving surface properties [20]. Biermann et al. [21] established a simulation model to predict the surface roughness produced by ultrasonic vibration assisted milling, and verified by experiments to well explain the variation law of surface roughness. Lu et al. [22] developed a "step increment" discrete simulation model to predict the typical textures and interference textures of ultrasonic vibration assisted milling, and revealed the relationship between ultrasonic vibration assisted milling parameters and machining quality. Hsu et al. [23] carried out the experiment of ultrasonic vibration assisted milling of nickel base alloy. The research shows that the application of ultrasonic vibration can not only reduce the cutting temperature, but also improve the surface quality. Suárez et al. [24] studied the effect of ultrasonic vibration assisted milling on the fatigue life of nickel base and found that the performance of material surface was greatly improved after vibration, which was $14.74 \%$ higher than that of traditional milling. Many conclusions of scholars prove that the research on ultrasonic vibration assisted micromilling (UVAMM) is of inestimable value.

At present, it is still a difficult problem to solve the micromilling surface problem of Inconel718. In this study, the ultrasonic vibration in the feed direction is applied to the workpiece. Combined with the factors such as cutting force and tool wear, the formation causes of ultrasonic vibration assisted micro milling surface are analyzed, and the effect of ultrasonic vibration on surface corrosion resistance is studied.

\section{Trajectory equation of cutting edge}


According to the motion characteristics of the tool in Fig. 1, it can be found that the tool tip trajectory of $\mathrm{MM}$ is a composite motion of rotation motion and feed motion. The trajectory of the $i$ th $(i=1,2)$ tool tip can be expressed by Eq. (2) and Eq. (3).

$$
\begin{gathered}
\theta=2 \pi n t \\
x_{i}=v_{f} t+(-1)^{i-1} r \sin (2 \pi n t) \\
y_{i}=(-1)^{i-1} r \cos (2 \pi n t)
\end{gathered}
$$

In this study, the process method of workpiece vibration is used to realize the purpose of vibration cutting. In order to more clearly express the position relationship between the tool and the workpiece, the vibration of the workpiece can be equivalent to the sinusoidal motion of the tool in the feed direction. The trajectory of the $i$ th tool tip can be expressed by Eq. (4) and Eq. (5).

$$
\begin{gathered}
x_{i}=v_{f} t+(-1)^{i-1} r \sin (2 \pi n t)+A \sin (\lambda \omega t) \\
y_{i}=(-1)^{i-1} r \cos (2 \pi n t)
\end{gathered}
$$

Where $v_{f}$ is the feed rate; $n$ is the spindle speed; $r$ is the tool radius; $A$ is the amplitude; $\lambda$ is the ratio of the vibration frequency to the spindle rotation frequency; $\theta$ is the rotation angle; $\omega$ is the ultrasonic vibration angular frequency.

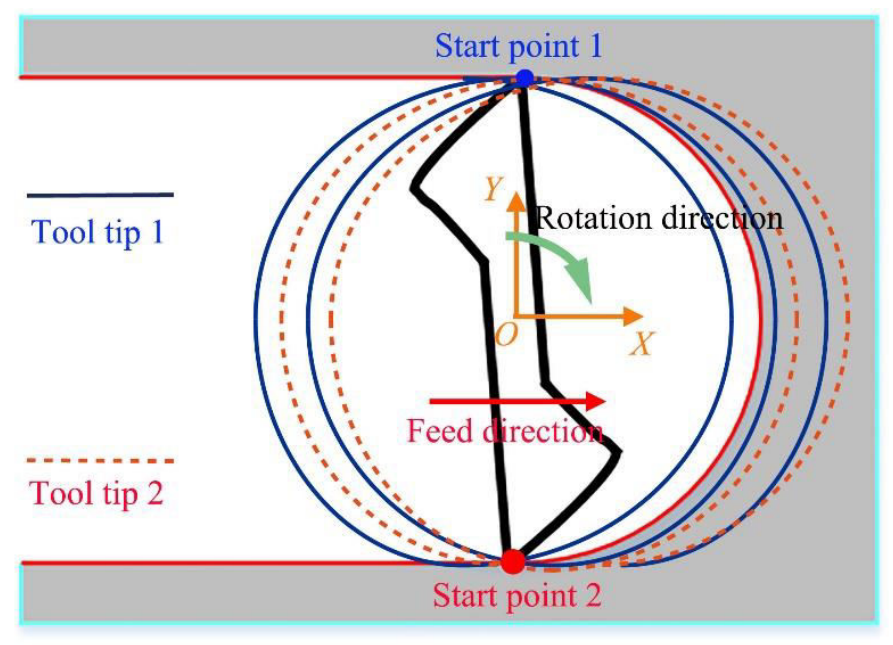

Fig. 1. Schematic diagram of tool tip path.

Fig. 2 shows the effects of amplitude $(A)$ and feed per tooth $\left(f_{\mathrm{z}}\right)$ on the tool tip trajectory. As can be seen from the figure, when $f_{\mathrm{z}}$ is $4 \mu \mathrm{m} / \mathrm{z}$, and $A$ is $3 \mu \mathrm{m}$, the repeated cutting process occurs. However, when the feed rate per tooth is $6 \mu \mathrm{m} / \mathrm{z}$, and $A$ is $3 \mu \mathrm{m}$, there is no repeated cutting process. This phenomenon is the result of the joint action of $A$ and $f_{\mathrm{z}}$. The larger $A$ or the smaller the feed rate per tooth will promote intermittent cutting. According to the characteristics of the tool tip trajectory, it can be concluded that the motion trajectory of the tool tip 2 and the tool tip 1 intersects when $A / f_{\mathrm{z}}>1 / 2$, which can meet the chip breaking requirements. Shen et al. $[13,14]$ also simulated the motion trajectory of the tool tip, and the results showed that when the tool tip trajectory intersects, the cutting process changes to intermittent cutting. 
(a)

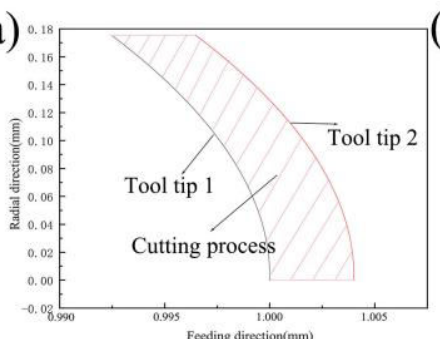

(d)

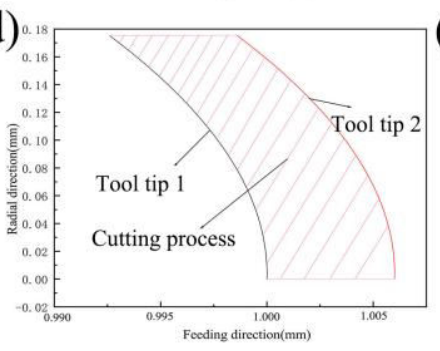

(b)

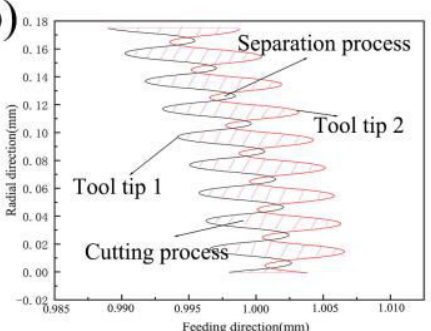

(c)

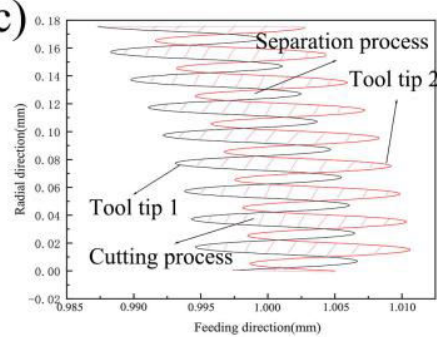

(e)

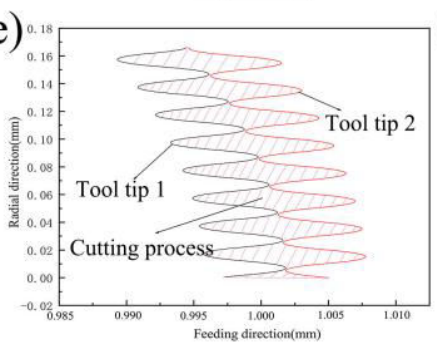

(f)

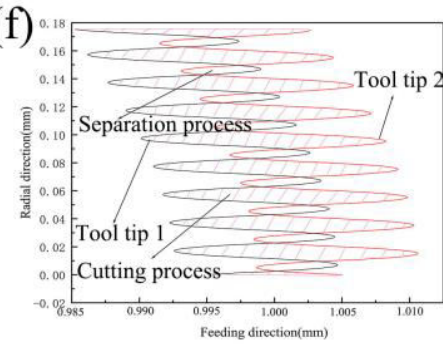

Fig. 2. Simulation of tool tip trajectory (a): $f_{\mathrm{z}}=4 \mu \mathrm{m} / \mathrm{z}, A=0 \mu \mathrm{m}$; (b): $f_{\mathrm{z}}=4 \mu \mathrm{m} / \mathrm{z}, A=3 \mu \mathrm{m}$; (c): $f_{\mathrm{z}}=4 \mu \mathrm{m} / \mathrm{z}, A=6 \mu \mathrm{m}$; (d): $f_{\mathrm{z}}=6 \mu \mathrm{m} / \mathrm{z}, A=0 \mu \mathrm{m}$; (e): $f_{\mathrm{z}}=6 \mu \mathrm{m} / \mathrm{z}, A=3 \mu \mathrm{m}$; (f): $f_{\mathrm{z}}=6 \mu \mathrm{m} / \mathrm{z}, A=6 \mu \mathrm{m}$.

\section{Experimental process}

\subsection{Cutting experiment}

In order to study the surface quality of UVAMM Inconel718, machining experiments were carried out on the four-axis precision milling machine, and ultrasonic vibration was applied to the workpiece through USM-300A ultrasonic equipment. The connection relationship of the experimental equipment is shown in Fig. 3. The cutting force was measured by Kistler 9129AA three-way dynamometer, the tool wear morphology was analyzed by scanning electron microscope (SEM), and the surface was analyzed by a three-dimensional texture morphology acquisition system and a super-high magnification lens zoom 3D microscope. The micromilling cutter is a cemented carbide double-edged flat end mill with UT coating, as shown in Fig. 4. The geometric parameters of the tool are shown in Table 1. The workpiece material is Inconel718 alloy, and its chemical composition is shown in Table 2. The experimental parameters are shown in Table 3 and Table 4. 


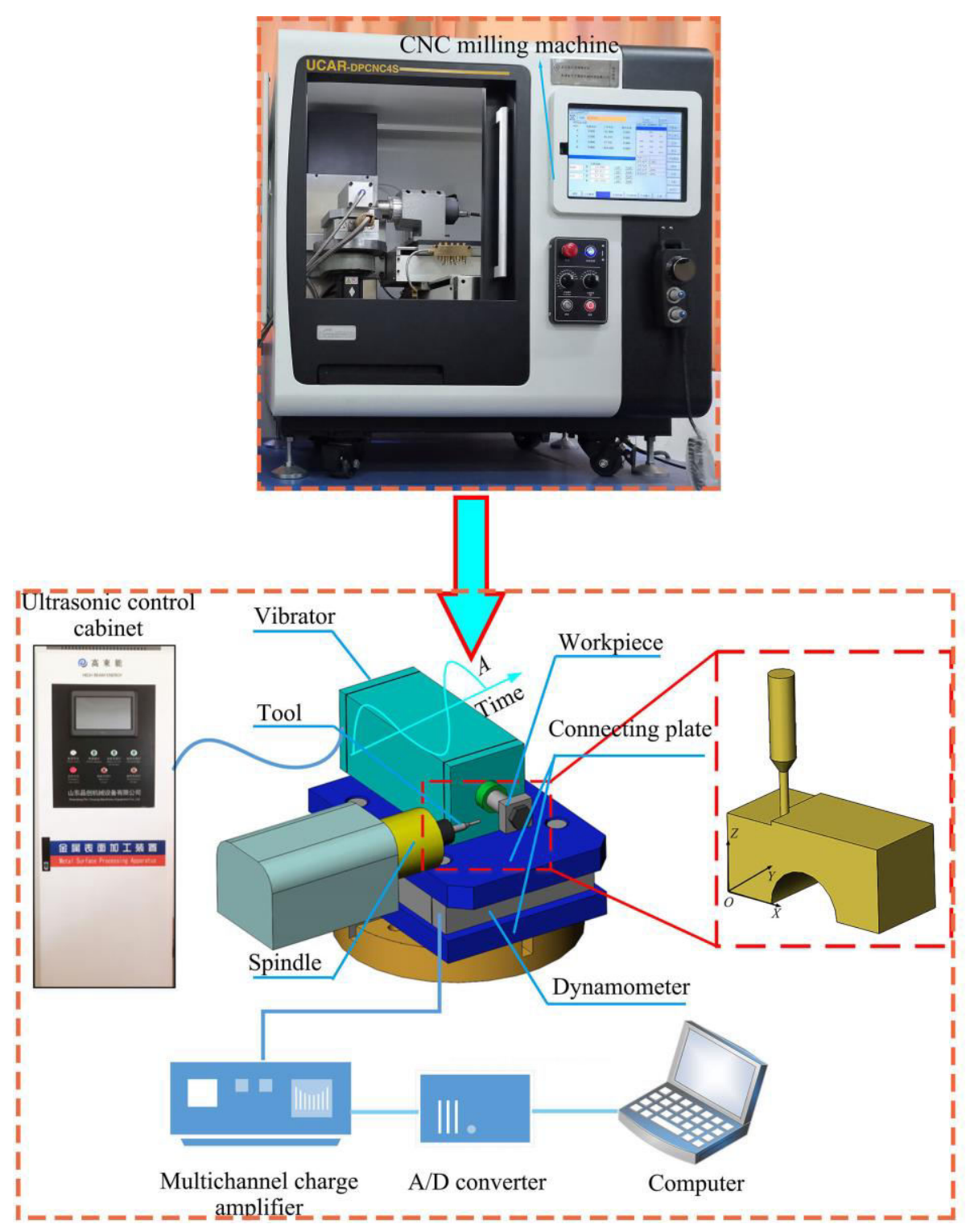

Fig. 3. Experimental equipment.

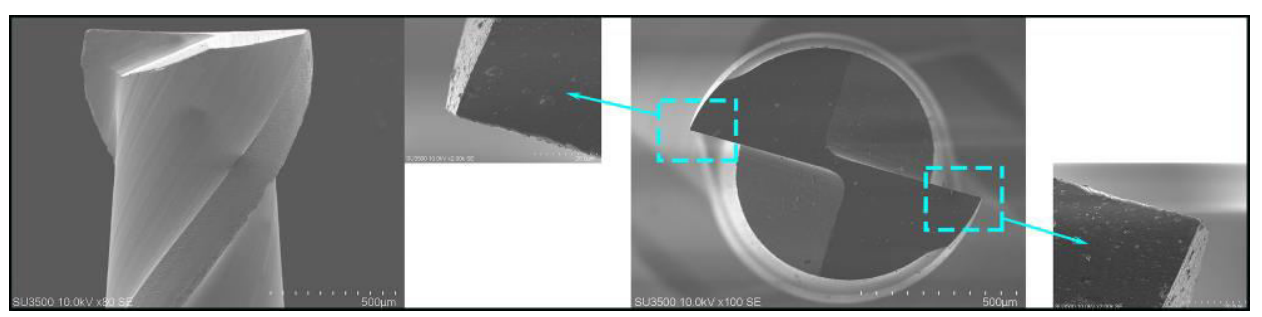

Fig. 4. Shape of micromilling cutter (SEM).

Table 1 Geometrical parameters of micromilling tool.

\begin{tabular}{cccc}
\hline Geometrical characteristic & Parameter value & Geometrical characteristic & Parameter value \\
\hline Tool diameter $(\mathrm{mm})$ & 1 & Rake angle of side edge $\left(^{\circ}\right)$ & 0 \\
Blade length $(\mathrm{mm})$ & 4 & Rear angle of side edge $\left({ }^{\circ}\right)$ & 9
\end{tabular}


Table 2 Main chemical components of Inconel 718.

\begin{tabular}{ccccccc}
\hline Element & $\mathrm{Ni}$ & $\mathrm{Cr}$ & $\mathrm{Fe}$ & $\mathrm{Nb}$ & $\mathrm{S}$ & $\mathrm{Ti}$ \\
\hline $\mathrm{wt} \%$ & 54.59 & 19.16 & 18.66 & 4.85 & 1.69 & 1.05 \\
\hline
\end{tabular}

Table 3 The first set of cutting parameters.

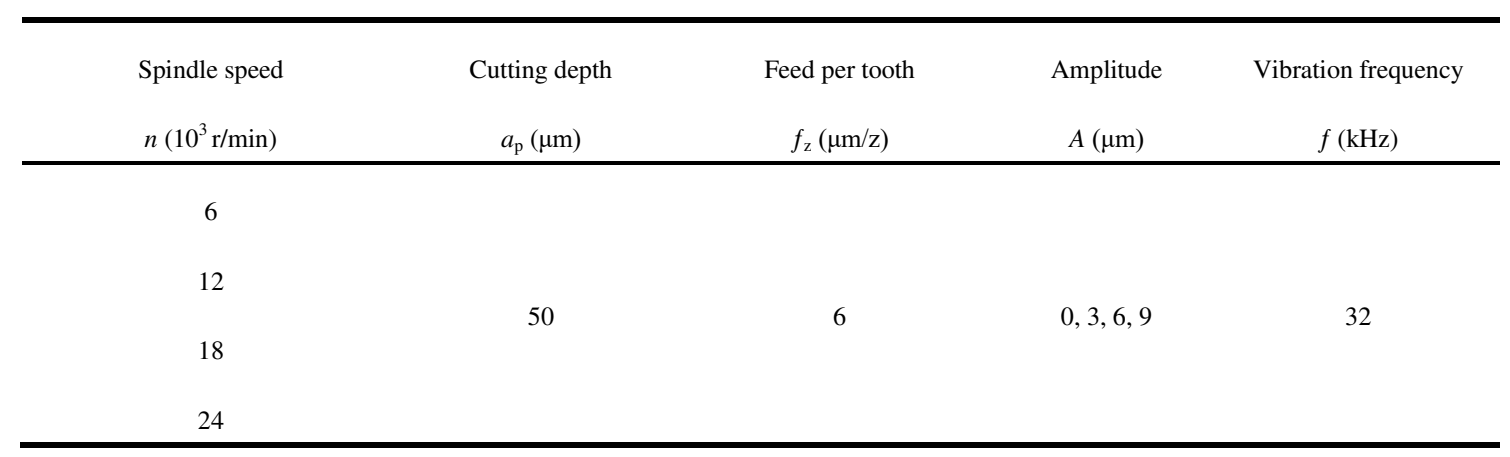

Table 4 The second set of cutting parameters.

\begin{tabular}{|c|c|c|c|c|}
\hline $\begin{array}{l}\text { Spindle speed } \\
n\left(10^{3} \mathrm{r} / \mathrm{min}\right)\end{array}$ & $\begin{array}{l}\text { Cutting depth } \\
\qquad a_{\mathrm{p}}(\mu \mathrm{m})\end{array}$ & $\begin{array}{l}\text { Feed per tooth } \\
\qquad f_{z}(\mu \mathrm{m} / \mathrm{z})\end{array}$ & $\begin{array}{l}\text { Amplitude } \\
\qquad A(\mu \mathrm{m})\end{array}$ & $\begin{array}{c}\text { Vibration frequency } \\
\qquad f(\mathrm{kHz})\end{array}$ \\
\hline 12 & 50 & $\begin{array}{l}2 \\
3 \\
4 \\
5 \\
6 \\
7 \\
8\end{array}$ & $0,3,6,9$ & 32 \\
\hline
\end{tabular}

\subsection{Corrosion experiment}

In the corrosion experiment, the electrochemical workstation with the model of Gamry Interface 1000 is used to simulate the corrosion resistance of the surface of Inconel718 material by MM and UVAMM in acidic oil and gas field environment. The connection relationship of the device is shown in Fig. 5. In the experiment, the working electrode is the sample to be corroded (Fig. 6), the reference electrode is a saturated calomel electrode ( $\mathrm{SCE}\left(\mathrm{Hg} / \mathrm{Hg}_{2} \mathrm{Cl}_{2}\right.$. Saturated $\left.\mathrm{KCl}\right)$ ), and the counter electrode is a platinum sheet arranged in parallel. The electrolyte is a mixed solution of $5 \% \mathrm{NaCl}$ and $0.4 \% \mathrm{Na}_{2} \mathrm{~S} \cdot 10 \mathrm{H}_{2} \mathrm{O}$, and the thermostatic water bath with model $\mathrm{HH}-2$ is used to heat and maintain the temperature of the electrolytic cell to $80{ }^{\circ} \mathrm{C}$. Before the experiment, the electrolyte was blown to saturation with $\mathrm{CO}_{2}$ with purity of $99.999 \%$, and continued to be blown during the experiment. Parameter setting: the corrosion area is $0.88 \mathrm{~cm}^{2}$, the scanning rate is $2.0 \mathrm{mV} / \mathrm{s}$, the initial voltage is $-0.5-1.5 \mathrm{~V}$, the frequency is 100 $\mathrm{kHz}$, and the chemical equivalent of Inconel718 is $29.36 \mathrm{~g} / \mathrm{F}$. 


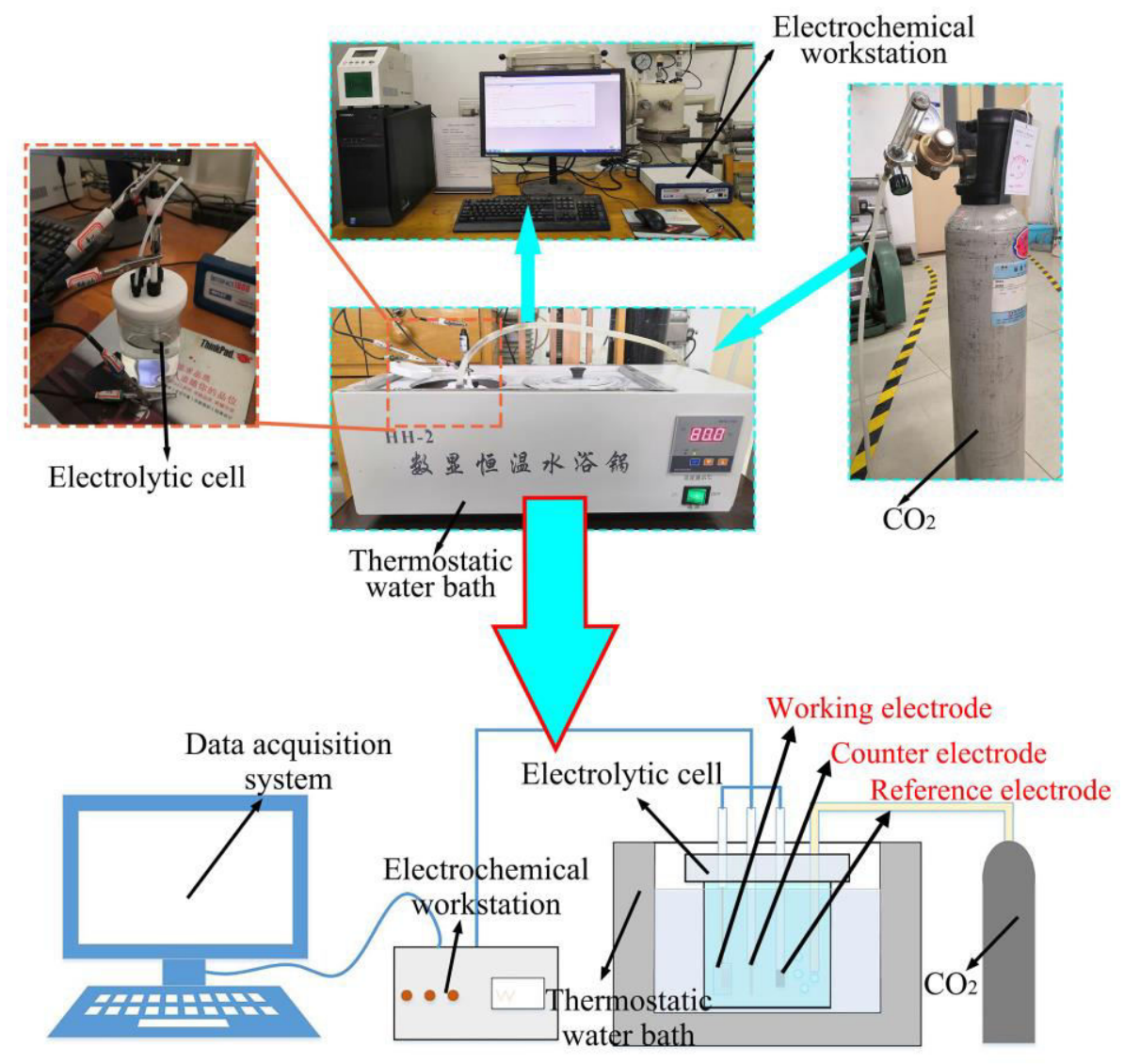

Fig. 5. Experimental equipment.

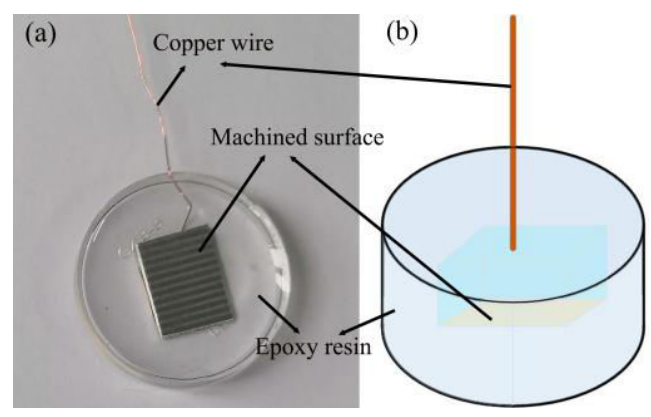

Fig. 6. Embedded workpiece.

\section{Results and discussion}

\subsection{Influence of cutting parameters on cutting force}

(1) Influence of ultrasonic vibration on cutting force at different $n$

From Fig. 7(a), (b) and (c), it can be seen that axial force $F_{\mathrm{z}}$ is more awesome with the increase of $n$, and radial force $F_{\mathrm{x}}$ and feed force $F_{\mathrm{y}}$ decrease first and then increase. After the vibration is applied, $F_{\mathrm{x}}$ decreases obviously, especially when $A$ is $6 \mu \mathrm{m}$ is the most obvious because intermittent cutting reduces the average cutting force. When $A$ is $9 \mu \mathrm{m}, F_{\mathrm{y}}$ of UVAMM is slightly larger than that of MM, because the ultrasonic vibration in the feed direction increases the impact force between the tool tip and the material, and the effect of the impact force is much higher than that of intermittent cutting. As can 
be seen from Fig. 7(d), resultant force $F_{\mathrm{r}}$ of MM first decreases and then increases with the increase of $n$. This is because when $n$ is low, the kinetic energy of the tool tip is small, and it is more difficult to remove the material. At this time, the ductile fracture of the material is more serious, and $F_{\mathrm{r}}$ is more large. The higher $n$, the greater the kinetic energy of the tool tip, the greater the impact force on the tool, and the higher the cutting temperature. The thermal softening effect increases the cutting resistance, so $F_{\mathrm{r}}$ is greater. When $A$ is $6 \mu \mathrm{m}, F_{\mathrm{r}}$ is the smallest, and $A$ is too large, which is not conducive to reducing the cutting force, so it is necessary to select a moderate $A$.
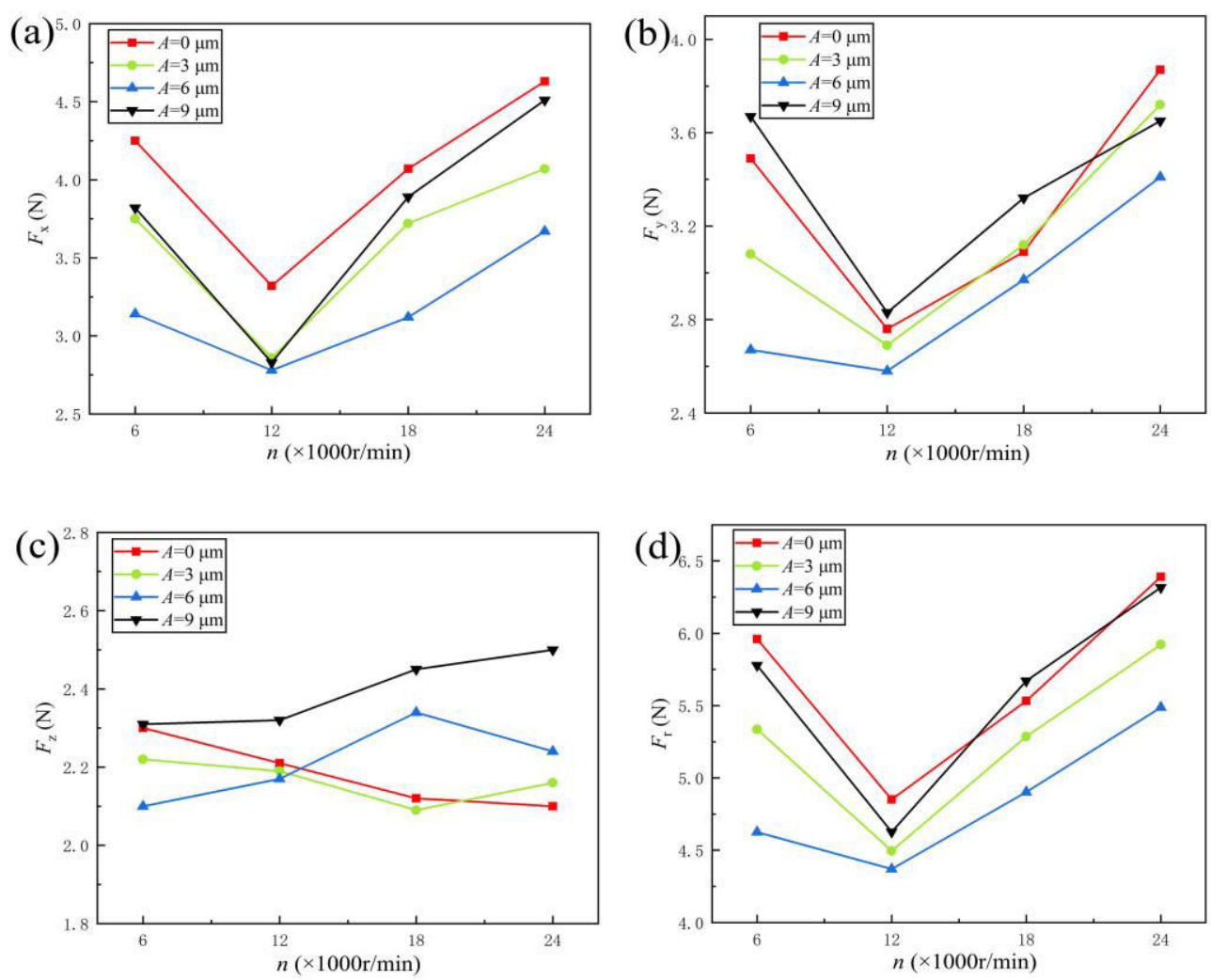

Fig. 7. Variation of cutting force under different $n$ (a): $F_{\mathrm{x}}$; (b): $F_{\mathrm{y}}$; (c) $F_{\mathrm{z}} ;$ (d): $F_{\mathrm{r}}\left(f_{\mathrm{z}}=6 \mu \mathrm{m} / \mathrm{z}, a_{\mathrm{p}}=50 \mu \mathrm{m}\right)$.

(2) Influence of ultrasonic vibration on cutting force under different $f_{\mathrm{z}}$

As can be seen from Fig. 8(a), (b) and (c), with the increase of $f_{\mathrm{z}}, F_{\mathrm{x}}, F_{\mathrm{y}}$ and $F_{\mathrm{z}}$ first decrease and then increase, in which $F_{\mathrm{x}}$ and $F_{\mathrm{y}}$ increase rapidly and $F_{\mathrm{z}}$ increase slowly. This is because increasing $f_{\mathrm{z}}$ will increase the volume of material to be removed and then increase the cutting resistance, which has little effect on $F_{\mathrm{z}}$. When $f_{\mathrm{z}}$ is small, the ultrasonic vibration increases each component force. When $f_{\mathrm{z}}$ is large, the ultrasonic vibration reduces each component force. This is because the ultrasonic vibration increases the instantaneous cutting thickness during small feed, and the intermittent cutting plays a decisive role during large feed. This is because when $f_{\mathrm{z}}$ is less than the cutting edge radius, chip is not easy to produce, and the ploughing effect between the tool tip and the material is particularly serious. However, when $f_{\mathrm{z}}$ is large enough, micro-scale cutting changes to macro-scale cutting, and the influence of cutting thickness on cutting force becomes more important. 

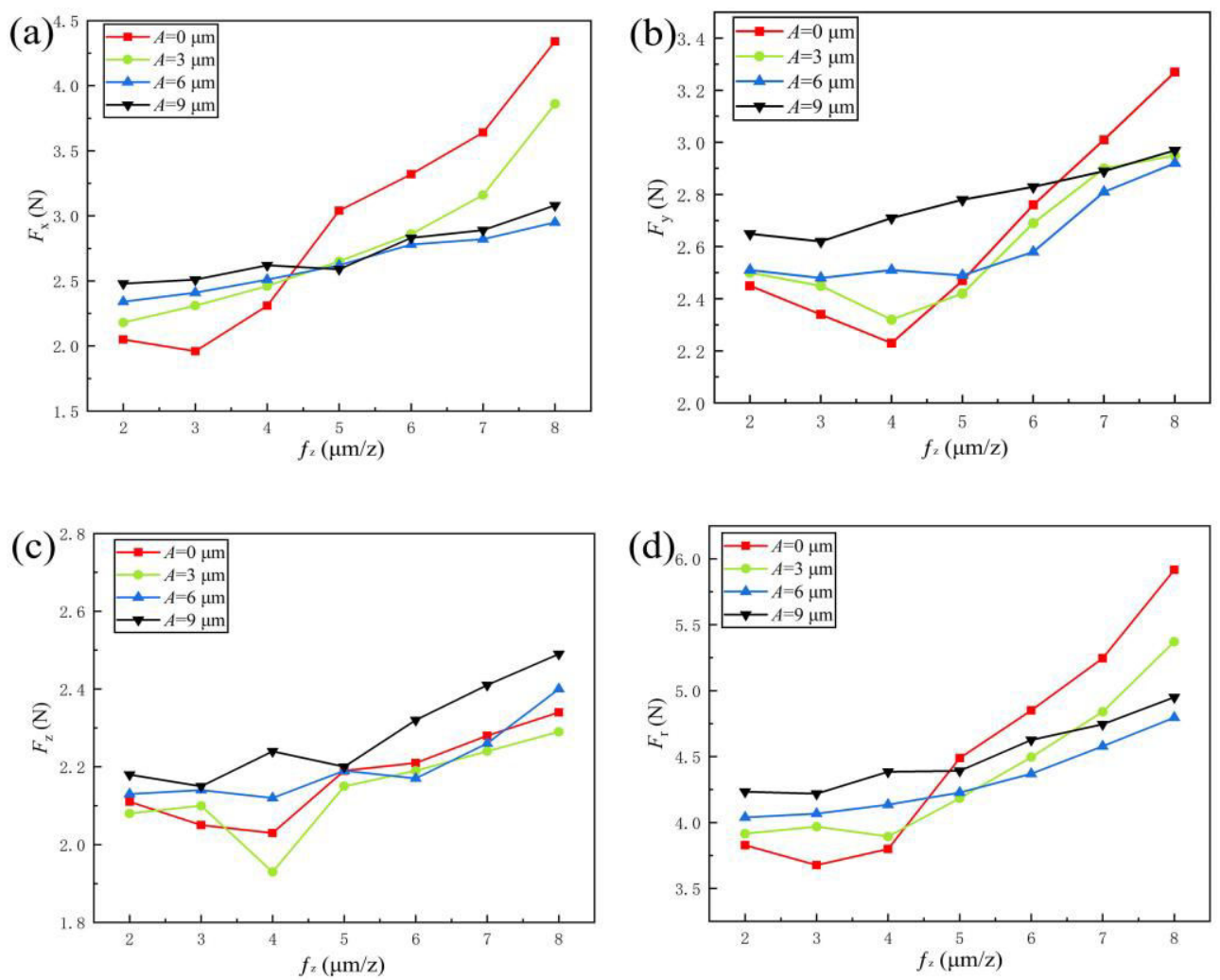

Fig. 8. Variation of cutting force under different $f_{\mathrm{z}}(\mathrm{a}): F_{\mathrm{x}} ;(\mathrm{b}): F_{\mathrm{y}} ;(\mathrm{c}): F_{\mathrm{z}} ;(\mathrm{d}): F_{\mathrm{r}}\left(n=12000 \mathrm{r} / \mathrm{min}, a_{\mathrm{p}}=50 \mu \mathrm{m}\right)$.

\subsection{Influence of ultrasonic vibration on tool wear}

Fig. 9 shows the tool morphology without machining experiment. The cutting edge is a straight linear structure, and the tool tip has a small arc, which will increase the strength of the tool tip and improve the service life of the tool.

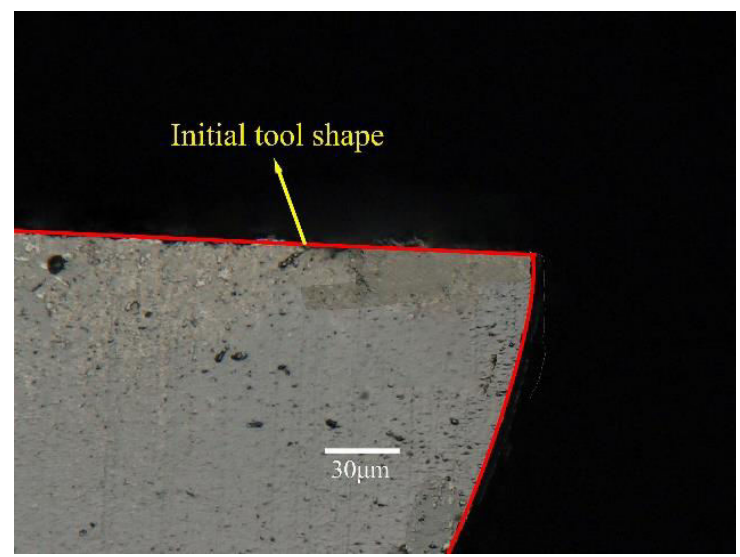

Fig. 9. Tool morphology.

The tool wear after cutting experiment was analyzed by scanning electron microscope (SEM) and energy disperse spectroscopy (EDS), as shown in Fig. 10. It can be seen from the figure that the tool tips of MM and UVAMM are silver white. Through the analysis of chemical elements in the tool tip area, it can be concluded that the contents of $\mathrm{W}, \mathrm{Ni}$ and $\mathrm{Fe}$ in the wear area increase sharply, indicating that the coating on the tool tip is peeling off and bonded with silver white material. 
As can be seen from Fig. 10(a), the tool tip area after MM has obvious wear of flank of base edge and side edge. The tool tip is seriously worn, but there is no obvious edge collapse. Due to the high temperature in the tool tip area and chip adhesion in the micromilling process, an obvious built-up edge is formed. The existence of built-up edge will increase the arc radius of the tool tip, resulting in more serious ploughing effect in the subsequent cutting process. Wang et al. [25] believe that the existence of built-up edge is the main reason affecting the surface quality, so inhibiting the generation of built-up edge is an important prerequisite for improving the surface quality.

As can be seen from Fig. 10(b), when $A$ is $3 \mu \mathrm{m}$, the tool tip is slightly worn, and there is obvious wear of flank of base edge. Compared with MM, the wear of flank of side edge is smaller, there is no obvious chip accumulation, and only a small amount of material is bonded to the rake face.

As can be seen from Fig. 10(c), when $A$ is $6 \mu \mathrm{m}$, the wear of flank of side edge is small, the wear area of flank of base edge increases obviously, and there is no obvious material bonding and chip accumulation on the rake face, but slight wear.

As can be seen from Fig. 10(d), when $A$ is $9 \mu \mathrm{m}$, the wear of flank of side edge increases, the wear area of flank of base edge increases obviously, and the material bonding and more serious tool wear appear on the rake face. Compared with other situations, there is an obvious edge collapse phenomenon, which is because the larger $A$ increases the impact between the tool tip and the material and reduces the service life of the tool. The damaged tool will have an adverse impact on cutting performance and machining quality.

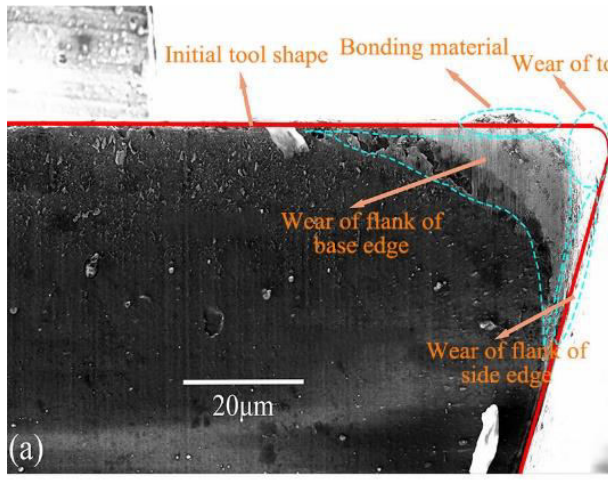

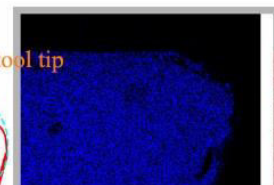

Al

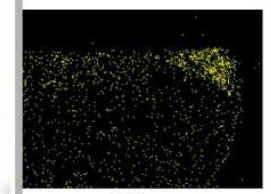

$\mathrm{Ni}$

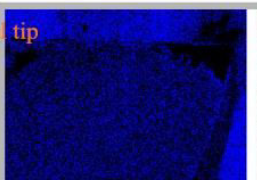

Al

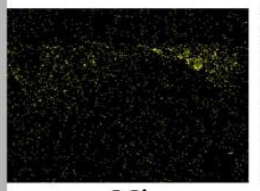

$\mathrm{Ni}$

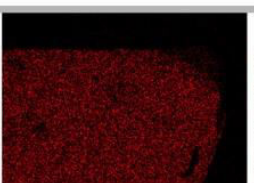

$\mathrm{Cr}$

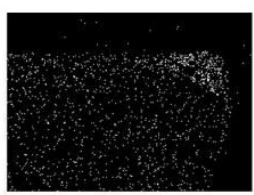

$\mathrm{Fe}$

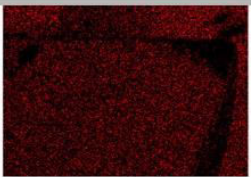

Cr

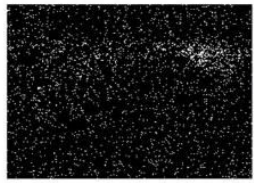

$\mathrm{Fe}$
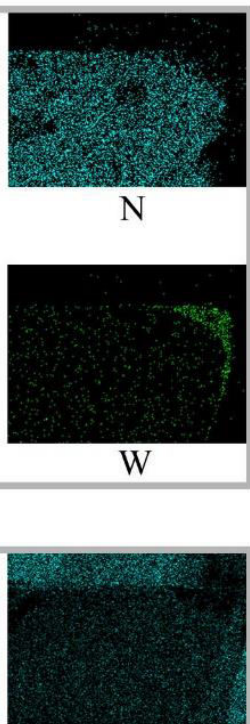

N

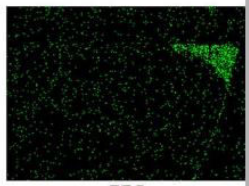

$\mathrm{W}$ 


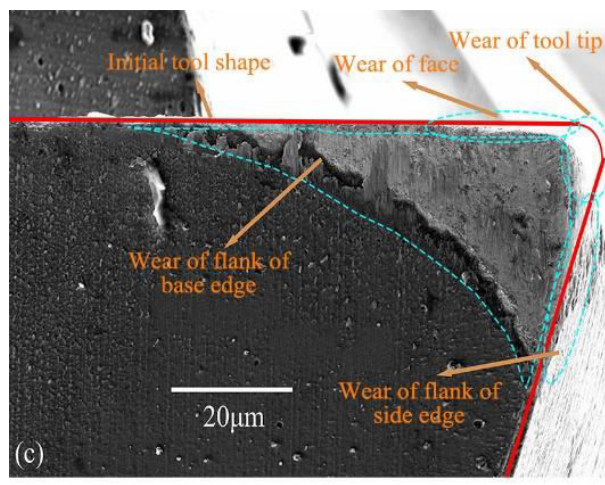

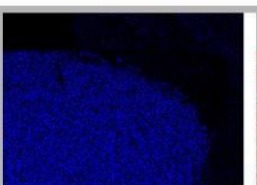

$\mathrm{Al}$

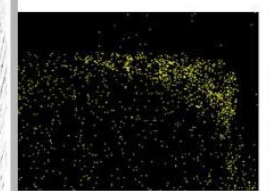

$\mathrm{Ni}$

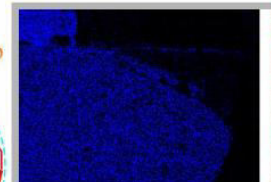

Al

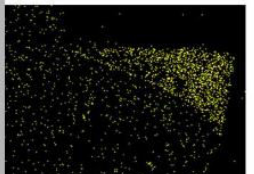

$\mathrm{Ni}$

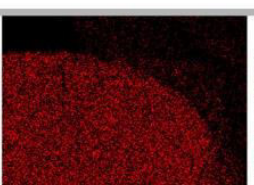

$\mathrm{Cr}$

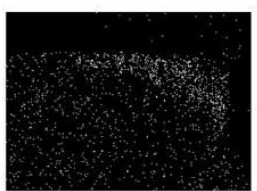

$\mathrm{Fe}$

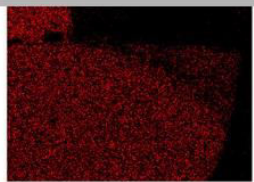

$\mathrm{Cr}$

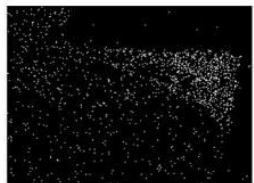

$\mathrm{Fe}$

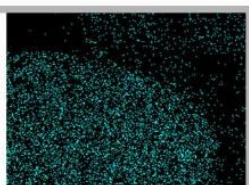

$\mathrm{N}$

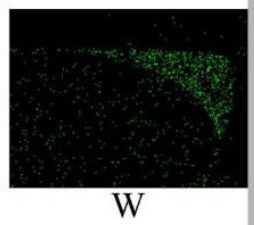

W

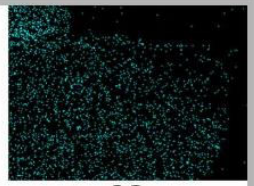

N

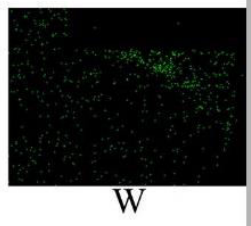

Fig. 10. Tool wear morphology and energy spectrum (a): $A=0 \mu \mathrm{m}$; (b): $A=3 \mu \mathrm{m}$; (c): $A=6 \mu \mathrm{m}$; (d): $A=9 \mu \mathrm{m}$.

\subsection{Influence of cutting parameters on surface quality}

(1) Micromilling surface defect morphology

In the micromilling process of Inconel718, $f_{\mathrm{z}}$ is small, and the ratio of cutting thickness to cutting edge radius is also small. In this case, the size effect plays an important role in material removal. It can be seen from the experiment that common surface defects such as humps, pits and gullies often appear on the bottom surface of micromilling groove, as shown in Fig. 11. These defects will seriously reduce the wear resistance and corrosion resistance of the surface. Due to the special properties of material matrix and the characteristics of microcutting, extrusion and scratching are the main forms of cutting, resulting in large strain and strain rate. The large amount of energy and friction heat consumed by plastic deformation will increase the cutting temperature in the deformation zone, soften the workpiece material, and cause serious blockage and accumulation in the machining process. Under the action of ploughing, the material accumulates with the sliding of the workpiece material and finally forms a hump, which is consistent with the conclusion in Ref. [26]. At the same time, due to the high binding force between material and tool or material and chip, the material is taken away in the cutting process and finally forms a pit. The existence of hard particles and built-up edge is inevitable, and there will be obvious gullies on the surface during processing [27]. Tool wear is a crucial factor in the formation of surface defects. Micromilling cutter is more prone to built-up edge, so the size effect is more obvious and the surface defects are more serious. 


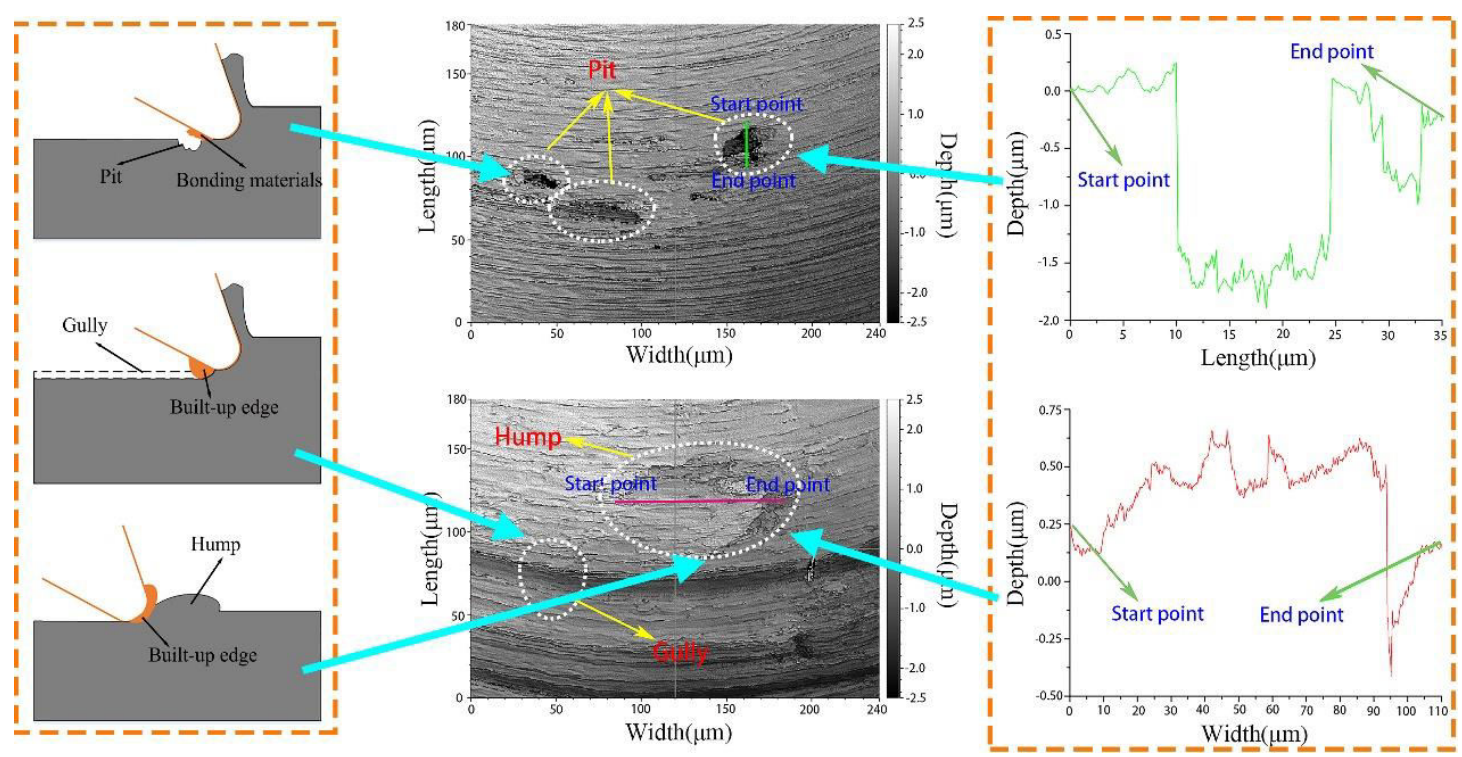

Fig. 11. Common micromilling surface defects.

(2) Surface morphology of UVAMM and MM

In the cutting process, MM and UVAMM will produce different morphologies, as shown in Fig. 12(a) and (b). The surface morphology of MM is similar to that of traditional milling, which is composed of uniform arc ridges. However, due to the easy adhesion between materials and tools in the machining process, there will be traces of adhesion on the surface of MM. UVAMM effectively inhibits the bonding phenomenon, reduces the surface defects, and forms a stepped and evenly distributed fish scale texture on the surface. Zhu et al. [28] also confirmed that the textured surface was of great significance to functional property, wear property and service life of components.

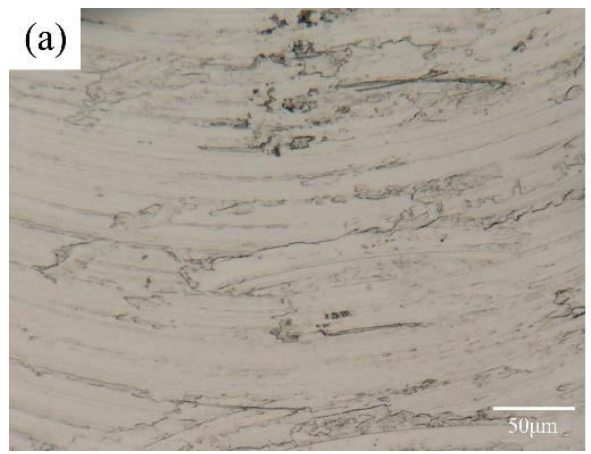

(b)

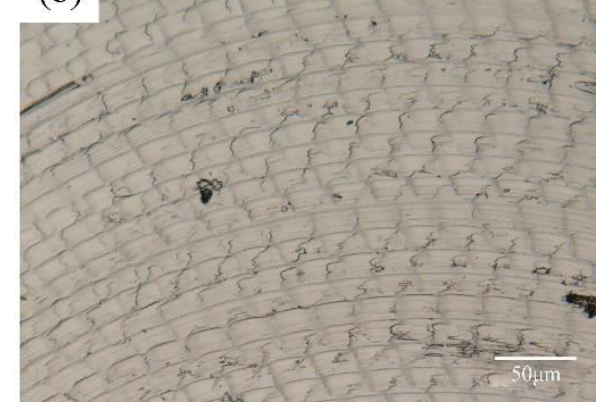

Fig. 12. Surface topography (a): traditional micro milling; (b): UVAMM.

(3) Influence of ultrasonic vibration on surface quality under different $n$

As can be seen from Fig. 13, when vibration is not applied, not only three surface defects but also opposite motion tracks will appear, which is caused by axial runout and affected by many factors such as machine tool stiffness, spindle accuracy and tool dimensional accuracy. When $n$ is $6000 \mathrm{r} / \mathrm{min}$, the surface quality is the worst, because serious extrusion deformation will occur at low $n$ and the bonding of materials is serious. Increasing $n$ will increase the stability, but it will also lead to thermal softening effect. After applying ultrasonic vibration, the bonding of materials will be significantly reduced. The lower $n$, the more times of vibration in each cycle is, and the closely textured network surface will be produced; The higher $n$, the more times of vibration in each cycle is, and a uniform and regular fish 
scale surface will be formed. When $n$ is $24000 \mathrm{r} / \mathrm{min}$ and $A$ is $6 \mu \mathrm{m}$, the fish scale texture is most obvious. It can also be seen from the figure that $A$ is $9 \mu \mathrm{m}$, the texture are no longer regular, and pits appear on the surface. On the one hand, it shows that if $A$ is too large, the vibration will seriously affect the machining stability. On the other hand, it shows that the tool tip is seriously worn and destroys the surface quality. Experiments show that when $n$ is about $12000 \mathrm{r} / \mathrm{min}$ and $A$ is $3-6 \mu \mathrm{m}$, the surface quality can be significantly improved.

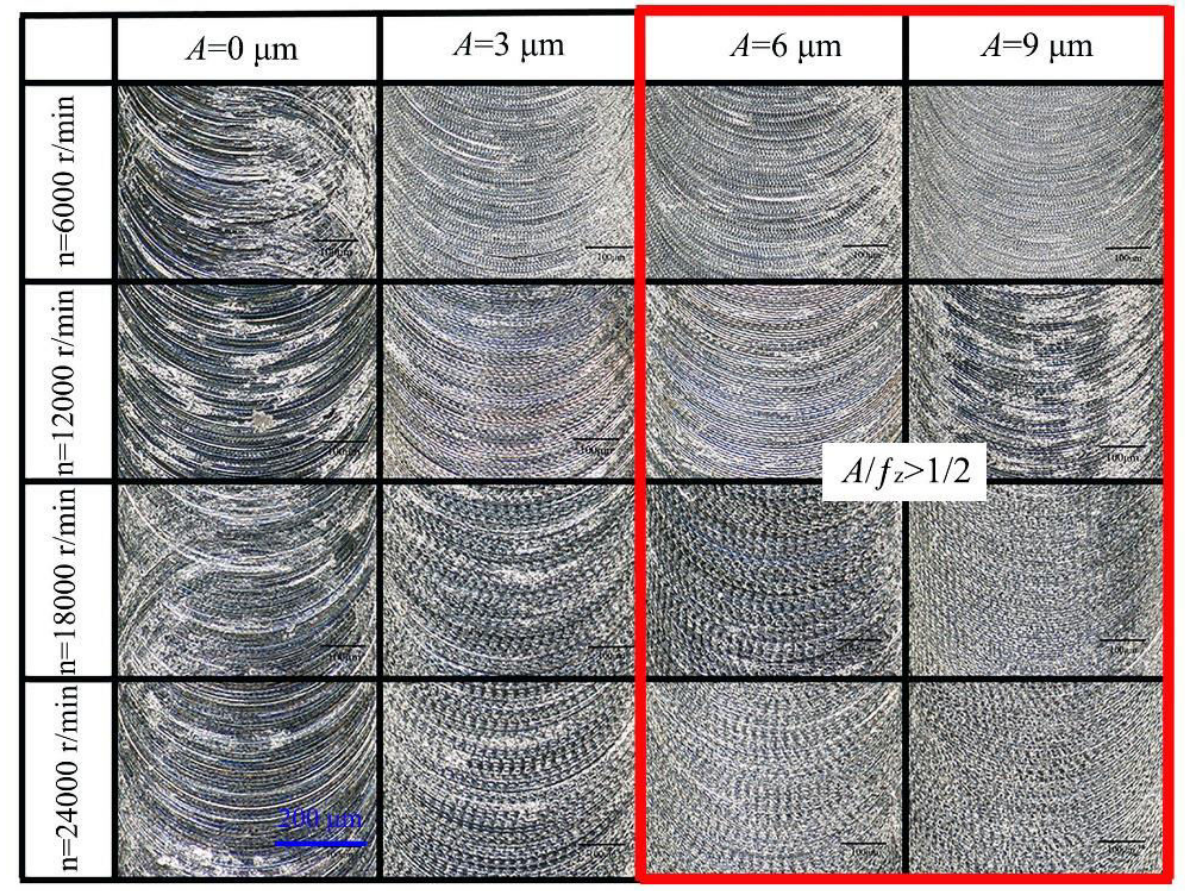

Fig. 13. Surface morphology under different $n$.

It can be seen from Fig. 14 that when ultrasonic vibration is not applied, the surface roughness first decreases and then increases with the increase of $n$. When $n$ is $12000 \mathrm{r} / \mathrm{min}$, the surface roughness is the smallest, and the minimum value is $0.134 \mu \mathrm{m}$. The reason for this trend may be that when $n$ is too low, the extrusion deformation between the cutting edge and the material is large, and the material and the tool are easy to bond, so the surface roughness is high. When $n$ increases, the volume of removed material increases, the degree of strain hardening deteriorates, and the cutting resistance increases, resulting in an increase in surface roughness [29]. Because excessive $n$ will lead to serious work hardening. In order to avoid the adverse impact of work hardening on the machining process, the appropriate $n$ should be selected for machining. On the other hand, higher $n$ will also produce higher temperature, which will make the material soften obviously, increase the plasticity of the material, increase the resistance of material removal, and make the tool adhere to the workpiece material in the machining process, so as to form an irregular machining surface. When ultrasonic vibration is applied, the surface roughness is reduced by about $20 \%$ compared with MM, and the change trend of surface roughness is the same as that of MM. This is because after ultrasonic vibration is applied, the cutting process is intermittent cutting, the chip breaking ability is enhanced, the cutting resistance is reduced, the tool sticking phenomenon is weakened, and the cutting process is more stable. However, when $A$ is $9 \mu \mathrm{m}$, the collision and extrusion between cutting edge and material is particularly serious, which seriously affects the machining stability and leads to the increase of surface roughness. 


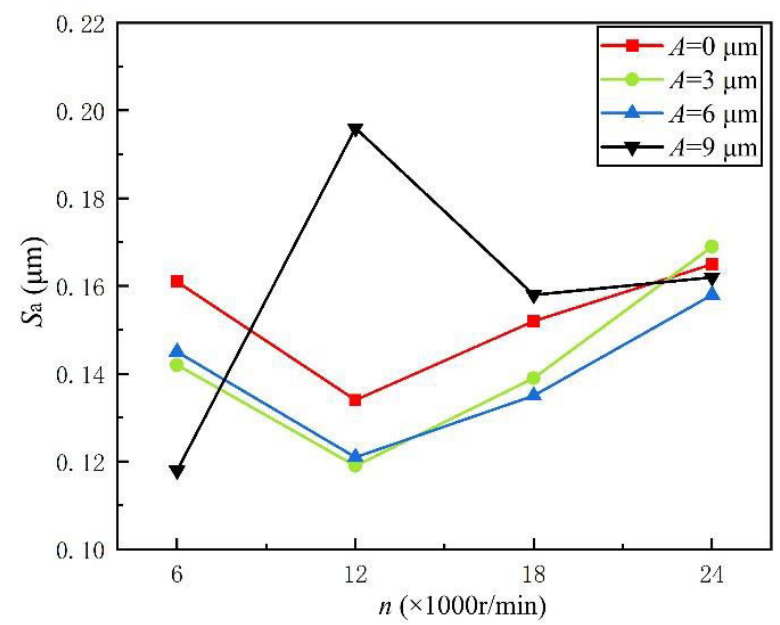

Fig. 14. Variation of surface roughness under different $n\left(f_{\mathrm{z}}=6 \mu \mathrm{m} / \mathrm{z}, a_{\mathrm{p}}=50 \mu \mathrm{m}\right)$.

(4) Influence of ultrasonic vibration on surface quality under different $f_{\mathrm{z}}$

It can be seen from Fig. 15 that when ultrasonic vibration is not applied, $f_{\mathrm{z}}$ is in the range of 2-5 $\mu \mathrm{m} / \mathrm{z}$, the surface texture is irregular, and serious surface defects appear, which is due to the difficulty of material removal in the micro-scale range. When $f_{\mathrm{z}}$ is $8 \mu \mathrm{m} / \mathrm{z}$, there are many gullies and pits on the surface due to large cutting amount, large cutting force and serious tool sticking. When $f_{\mathrm{z}}$ is $6 \mu \mathrm{m} / \mathrm{z}$ and $7 \mu \mathrm{m} / \mathrm{z}$, there are fewer surface defects such as humps, pits and gullies, and the surface quality is better. When $A$ of $3 \mu \mathrm{m}$ or $6 \mu \mathrm{m}$ is applied, the tool tip trajectory is more regular and the surface defects are significantly reduced. Combined with the change of surface roughness, the surface quality improvement effect is the most obvious with a small feed rate. The tool tip trajectory is the most regular when $f_{\mathrm{z}}$ is within 6-7 $\mu \mathrm{m} / \mathrm{z}$. When $A$ is $9 \mu \mathrm{m}$, serious pits and humps appear on the surface, especially when $f_{\mathrm{z}}$ is greater than $5 \mu \mathrm{m} / \mathrm{z}$, the phenomenon is the most serious, and its surface roughness is much higher than that of MM, indicating that too large $A$ will affect the stability of machining and damage the material surface in the machining process. 


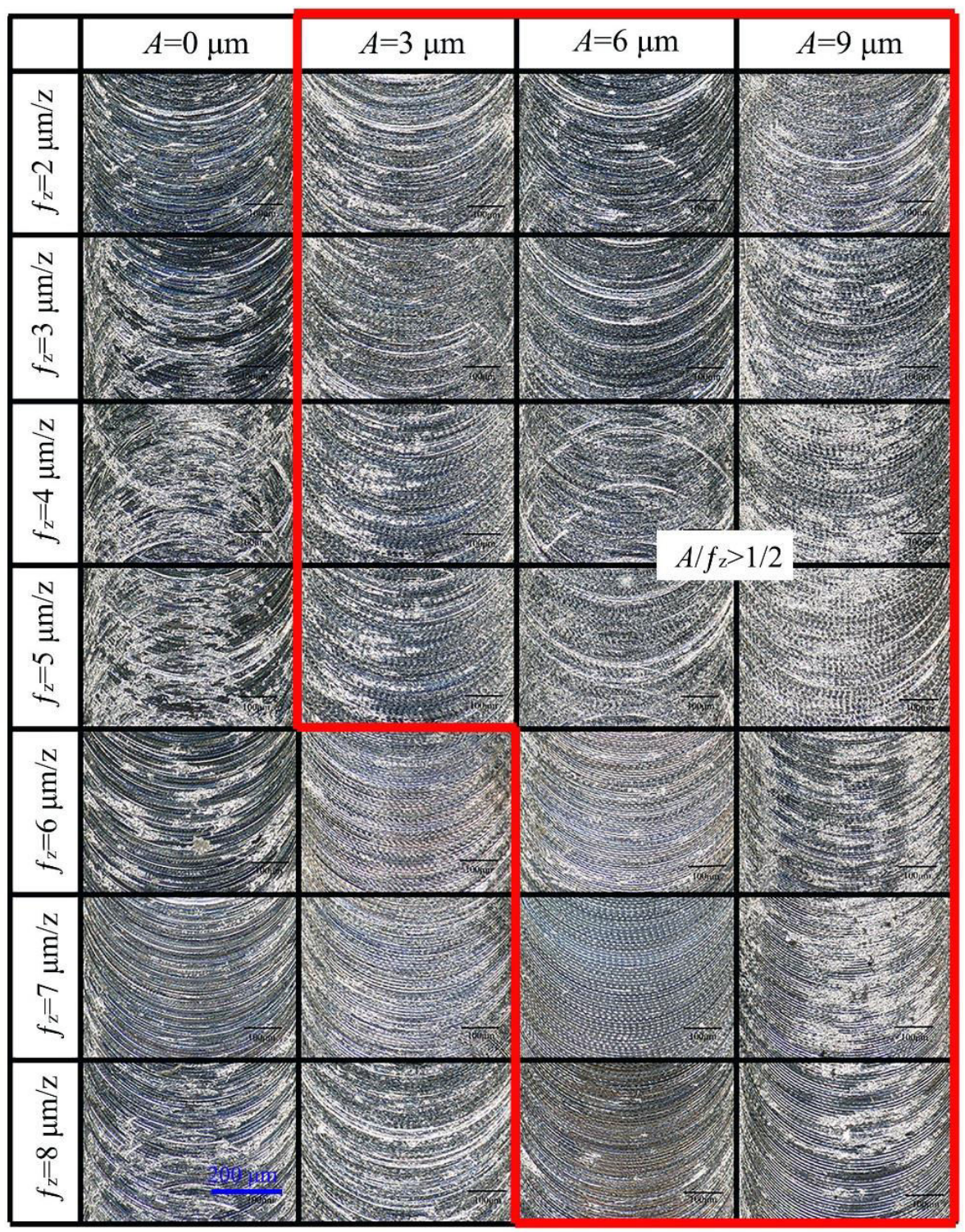

Fig. 15. Surface morphology under different $f_{\mathrm{z}}$.

As can be seen from Fig. 16, with the increase of $f_{\mathrm{z}}$, the surface roughness decreases continuously. When $f_{\mathrm{z}}$ exceeds $6 \mu \mathrm{m} / \mathrm{z}$, it increases again. In the process of MM, the smaller $f_{\mathrm{z}}$ is, the more serious the ploughing and the more serious the accumulation of materials is. At this time, there will be obvious elastic deformation, so the roughness increases. In addition, it is easy to adhere between the material and the tool, which will increase the surface defects, resulting in the increase of roughness. When the feed rate per tooth is large, plastic shear deformation is the main way to remove the material. Although the surface roughness decreases compared with that under the condition of small feed, the roughness will still increase with the increase of $f_{\mathrm{z}}$, mainly because the increase of $f_{\mathrm{z}}$ will increase the volume of removed material, making the removal of material more difficult, resulting in the increase of surface roughness. After applying ultrasonic vibration, the surface roughness has been significantly improved at low $A$. When $f_{\mathrm{z}}$ is less than $6 \mu \mathrm{m} / \mathrm{z}$, the three amplitudes have significantly improved the surface roughness, but the effect of small $A$ on reducing the surface roughness is more obvious. This is because the smaller $f_{\mathrm{z}}$, the more serious the size effect. The cutting process is mainly elastic deformation, and the material removal is difficult. However, the application of high frequency vibration changes the 
instantaneous cutting thickness, reduces the impact of size effect on surface roughness, improves the chip formation and chip breaking ability, and therefore reduces the surface roughness. When $f_{\mathrm{z}}$ is greater than $6 \mu \mathrm{m} / \mathrm{z}$, the effect of ultrasonic vibration is no longer obvious, because $f_{\mathrm{z}}$ is far greater than $A$, the chip breaking condition is not reached, and the separation between the tool and the workpiece is no longer obvious, and when $A$ is $9 \mu \mathrm{m}$, the surface roughness increases obviously, because when the chip breaking condition is not reached, the volume of removed material is increased, resulting in the increase of cutting force, which finally seriously affects the stability of the machining process. Therefore, the surface roughness is much higher than that of MM.

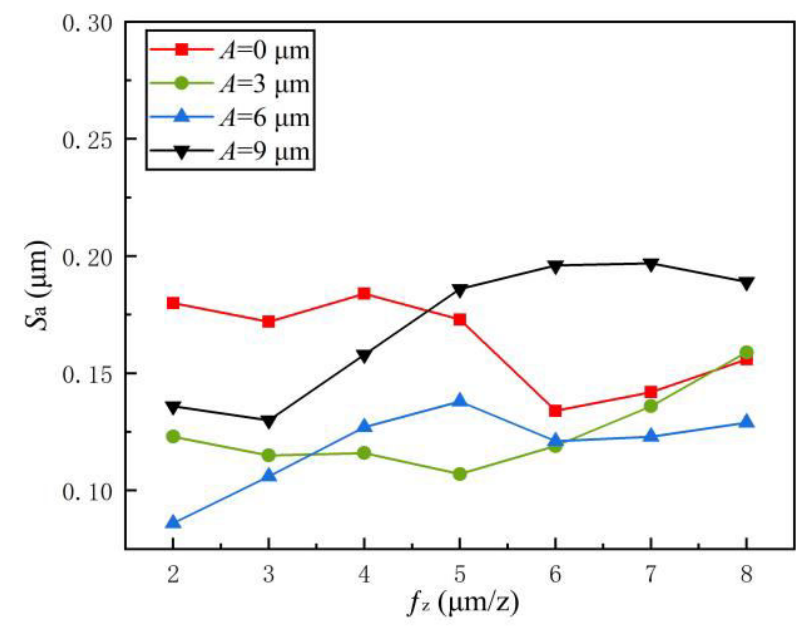

Fig. 16. Variation of surface roughness under different $f_{\mathrm{z}}\left(n=12000 \mathrm{r} / \mathrm{min}, a_{\mathrm{p}}=50 \mu \mathrm{m}\right)$.

\subsection{Analysis of surface corrosion resistance}

Fig. 17 shows the surface morphology of four groups of samples to be corroded. The surface obtained by MM has uniform arc tool marks and serious surface defects. Its surface roughness is $0.134 \mu \mathrm{m}$. Applying three different amplitudes will form a uniform fish scale surface. Under the three parameters, the surface defects are significantly reduced, and the surface roughness is $0.119 \mu \mathrm{m}, 0.121 \mu \mathrm{m}$ and $0.196 \mu \mathrm{m}$ respectively. The larger $A$ is, the wider the fish scale is, the more obvious the trace is, and the greater the surface roughness is. 


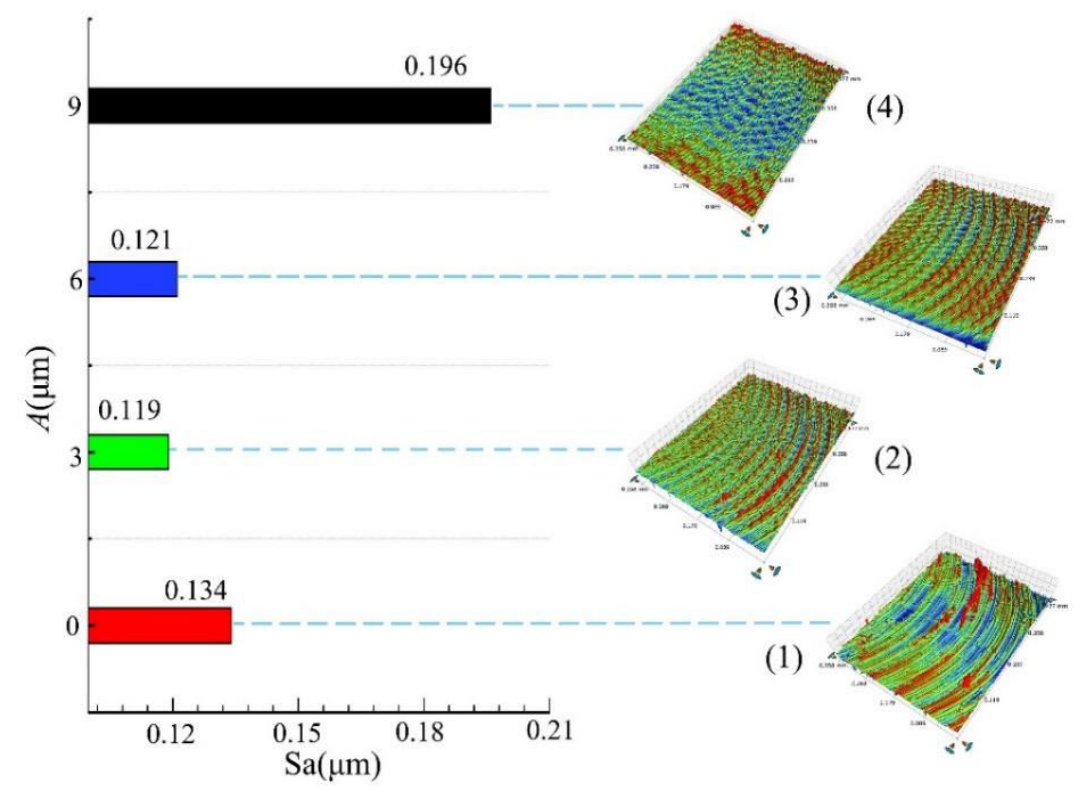

Fig. 17. Surface morphology of four groups of samples (1): $A=0 \mu \mathrm{m}$; (2): $A=3 \mu \mathrm{m}$; (3): $A=6 \mu \mathrm{m}$; (4): $A=9 \mu \mathrm{m}$.

The polarization test results are shown in Fig. 18. The self-corrosion potential ( $\left.E_{\text {corr }}\right)$, self-corrosion current $\left(I_{\text {corr }}\right)$ and corrosion rate are obtained by Tafel extrapolation method. The results are shown in Table 5, and the parameter relationship is shown in Fig. 19. As can be seen from Fig. 18, the surfaces produced by UVAMM have transient passivation. With the increase of potential, the current density rises sharply. At this time, the passivation film is broken and a corrosion reaction occurs. Then the potential continues to increase and a new protection film forms. When the new breakdown potential is reached, it will be further corroded, which is also the resistance in the corrosion process. As can be seen from Fig. 19, with the increase of $A$, the surface roughness decreases first and then increases, and the change trend of corrosion potential also decreases first and then increases. The surface roughness of sample 4 is the largest and the self-corrosion potential $\left(E_{\text {corr }}\right)$ is the highest. The larger $A$ is, the smaller the self-corrosion current $\left(I_{\text {corr }}\right)$ and corrosion rate is. The corrosion rate of sample 4 is the smallest and the corrosion resistance is the strongest. Compared with sample 1, the self-corrosion potential ( $\left.E_{\text {corr }}\right)$ of samples 2 and 3 is slightly larger, but the self-corrosion current $\left(I_{\text {corr }}\right)$ and corrosion rate are significantly reduced. Some studies show that the larger the surface roughness is, the larger the corrosion area is, and the worse the corrosion resistance of the surface is [30,31], which indicates that the corrosion resistance is not completely dependent on the surface roughness, but also affected by the surface morphology. 


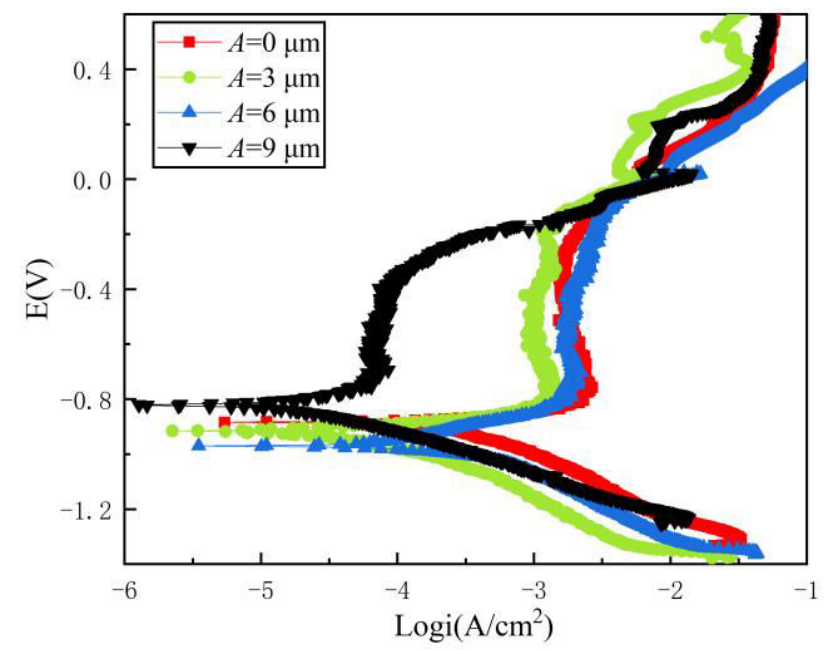

Fig. 18. Polarization curve.

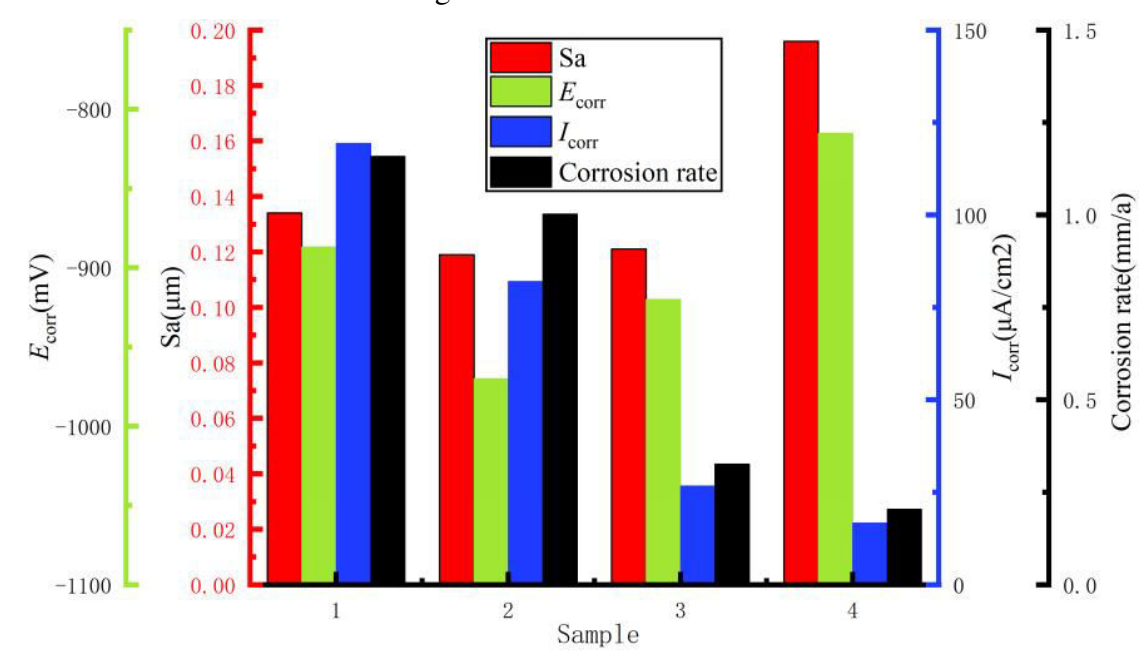

Fig. 19. Corrosion parameters.

Table 5 Corrosion parameters obtained by Tafel extrapolation

\begin{tabular}{ccccc}
\hline Sample & $\begin{array}{c}\text { Surface roughness } \\
\mathrm{Sa} /(\mu \mathrm{m})\end{array}$ & $\begin{array}{c}\text { self-corrosion potential } \\
E_{\text {corr }} /(\mathrm{mV})\end{array}$ & $\begin{array}{c}\text { self-corrosion current } \\
I_{\text {corr }} /\left(\mu \mathrm{A} / \mathrm{cm}^{2}\right)\end{array}$ & $\begin{array}{c}\text { Corrosion rate } \\
/(\mathrm{mm} / \mathrm{a})\end{array}$ \\
\hline 1 & 0.134 & -886.78 & 119.35 & 1.4589 \\
2 & 0.119 & -969.91 & 82.029 & 1.0027 \\
3 & 0.121 & -919.97 & 26.714 & 0.32654 \\
4 & 0.196 & -815.27 & 16.735 & 0.20457 \\
\hline
\end{tabular}

The Nyquist curve of this experiment is shown in Fig. 20. It can be seen from the figure that the shapes of the four groups of Nyquist impedance spectra are similar, all in arc shape, and the difference is that the radius of capacitive reactance arc is different. Some studies have pointed out that the larger the radius of the capacitive resistance arc is, the greater the reaction resistance to corrosion is, indicating that the corrosion resistance of the sample is better [32]. Among them, the radius of the capacitive resistance arc of sample 4 is the largest, which is several times that of other samples, followed by sample $3>$ sample $2>$ sample 1 . 


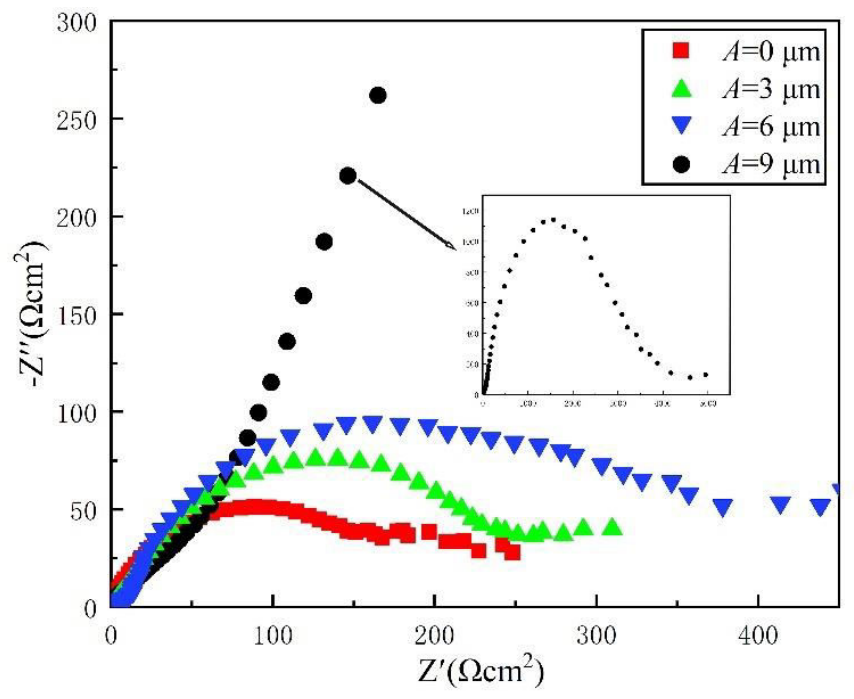

Fig. 20. Nyquist curve.

In order to accurately analyze the corrosion resistance of the four samples, ZSimpWin software is used to fit the Nyquist curve and obtain the equivalent circuit model. After comparing the fitting effects of the four groups of results, $R_{\mathrm{s}}\left(Q_{\mathrm{f}}\left(R_{\mathrm{f}}\left(C_{\mathrm{dl}} R_{\mathrm{ct}}\right)\right)\right.$ is finally selected as the equivalent circuit model, as shown in Fig. 21. In the equivalent circuit model, $R_{\mathrm{S}}$ is the electrolyte resistance, $Q_{\mathrm{f}}$ is the corrosion product film constant phase angle element, $R_{\mathrm{f}}$ is the corrosion product film resistance, $C_{\mathrm{dl}}$ is the electric double-layer capacitance, and $R_{\mathrm{ct}}$ is the charge transfer resistance. By establishing the equivalent circuit model, the estimation of relevant circuit elements is obtained, as shown in Table 6 . In the table, the $R_{\mathrm{ct}}$ of sample 4 is the largest and that of sample 1 is the smallest. Combined with the capacitive reactance arc in Nyquist diagram, it can be found that the larger the capacitive reactance arc is, the greater the $R_{\mathrm{ct}}$ is, the smaller the corrosion rate is and the stronger the corrosion resistance is. Compared with sample 1, sample 2 and sample 3 have smaller surface roughness and stronger corrosion resistance. The surface roughness of sample 4 is greater than that of the other three samples, but the corrosion resistance is the strongest, indicating that the corrosion resistance of the material surface is related not only to the roughness, but also to the surface morphology. The large-size fish scale surface has stronger corrosion resistance.

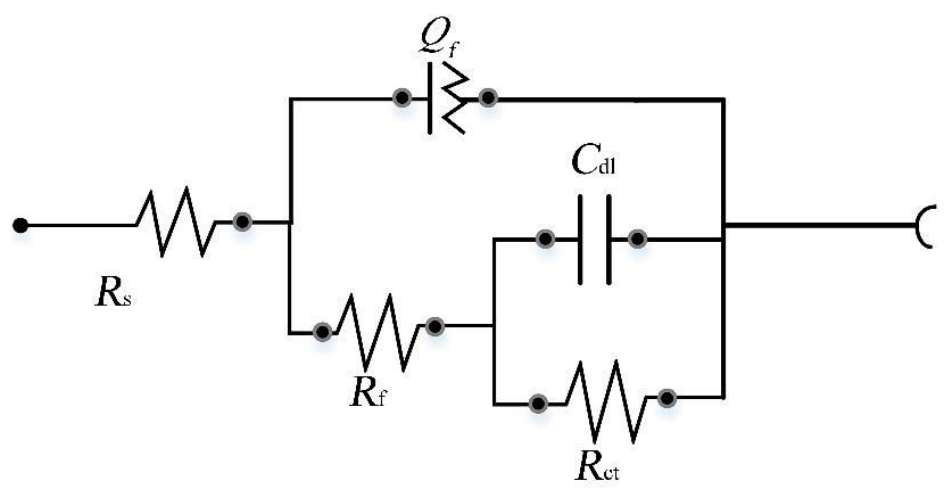

Fig. 21. Equivalent circuit model.

Table 6 Estimation of equivalent circuit components

\begin{tabular}{ccccc}
\hline parameter & Sample 1 & Sample 2 & Sample 3 & Sample 4 \\
\hline $\mathrm{R}_{\mathrm{s}}\left(\Omega \mathrm{cm}^{2}\right)$ & 2.127 & 1.910 & 1.979 & 5.855 \\
$\mathrm{Q}-\mathrm{Yo}\left(\Omega^{-1} \mathrm{~cm}^{-2} \mathrm{~s}^{\mathrm{n}}\right)$ & $1.984 \times 10^{-3}$ & $1.765 \times 10^{-3}$ & $1.694 \times 10^{-3}$ & $1.664 \times 10^{-4}$ \\
\hline
\end{tabular}




\begin{tabular}{ccccc}
\hline Q-n & 0.5008 & 0.4394 & 0.6009 & 0.5844 \\
$\mathrm{R}_{\mathrm{f}}\left(\Omega \mathrm{cm}^{2}\right)$ & 210.6 & 457.3 & 237.3 & 388.8 \\
$\mathrm{C}_{\mathrm{dl}}\left(\mathrm{Fcm}^{2}\right)$ & $8.626 \times 10^{-5}$ & $1.968 \times 10^{-4}$ & $1.253 \times 10^{-4}$ & $4.227 \times 10^{-5}$ \\
$\mathrm{R}_{\mathrm{ct}}\left(\Omega \mathrm{cm}^{2}\right)$ & 27.86 & 28 & 51.1 & 139.7 \\
\hline
\end{tabular}

Fig. 22 shows the corrosion morphology of the machined surface of four groups of samples. It can be seen from the figure that a large number of corrosion pits with large diameter and large number appear on the surface of sample 1, which may be due to the formation of a large number of surface defects due to the adhesion of materials on the micromilled surface during the machining process, which promotes the growth of corrosion pits. There are many corrosion pits with small diameter in sample 2 and sample 3, which may be due to the compact surface texture and more pores caused by ultrasonic vibration. The surface of sample 4 is relatively complete, and only a few corrosion pits with small size appear, which means that the larger the fish scale size, the more obvious the improvement effect on the surface corrosion resistance. Therefore, the fish scale surface formed by high $n$ and large $A$ can improve the surface corrosion resistance.
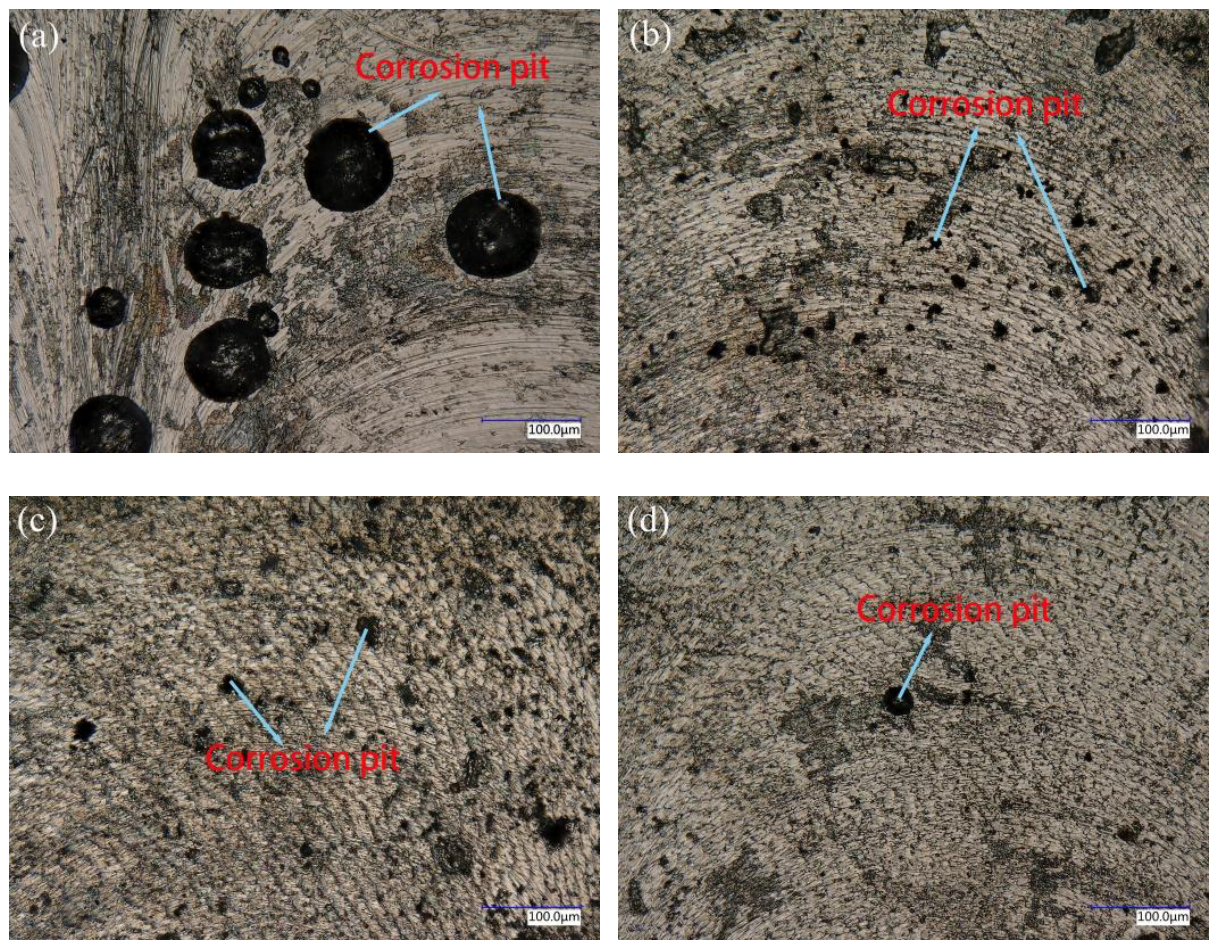

Fig. 22. Corrosion morphology (a): sample 1; (b): Sample 2; (c): sample 3; (d): sample 4.

\section{Conclusion}

In this study, the experiments of MM and UVAMM of Inconel718 are carried out, and the effects of ultrasonic vibration on cutting force, tool wear and surface quality are comprehensively analyzed. In addition, through electrochemical corrosion experiments, polarization curve, Nyquist curve and equivalent circuit model were drawn. Combined with surface roughness and surface morphology, the effects of different $A$ on surface corrosion resistance were studied, and the following experimental results were obtained:

(1) Through the simulation of tool tip trajectory, the characteristics of tool tip trajectory in UVAMM are analyzed. 
(2) Applying a small $A$ can effectively reduce the cutting force, inhibit the generation of built-up edge, and the wear of flank of side edge, increase the wear of flank of base edge. When $A$ is large, edge collapse will occur and the cutting force will sharply increase.

(3) In the micromilling process of Inconel718 alloy, it is easy to produce three common surface defects: pit, hump and gully. UVAMM can produce closely textured mesh surface. At high $n$, it will produce fish scale surface with obvious knife marks and uniform rules. When no vibration is applied, the surface roughness first decreases and then increases with the increase of $n$ and $f_{\mathrm{z}}$. After applying vibration, it is found that the improvement effect on surface quality is most obvious under the conditions of small $n$, small feed and moderate $A$. A larger $A$ will have an adverse impact on surface roughness. Therefore, the selection of $A$ should not be too large.

(4) UVAMM significantly improves the surface corrosion resistance of Inconel718 when $A$ is 9 $\mu \mathrm{m}$, self-corrosion potential $\left(E_{\text {corr }}\right)$ is the highest, the self-corrosion current $\left(I_{\text {corr }}\right)$ and corrosion rate are the smallest, the capacitive reactance arc is the largest, the $R_{\mathrm{ct}}$ is the largest, and the corrosion resistance is the best, which shows that the wide fish scale surface significantly improves the corrosion resistance of the surface.

Funding This reseach was supported by National Natural Science Foundation of China (52075275), Agricultural Key Applied Project of China (SD2019NJ015), Chuzhou Science and Technology Bureau Foundation of China (2020ZG004) and Tongling Science and Technology Bureau Foundation of China (20200101005).

Competing interests The authors declare that they have no competing interests.

Data Availability Not applicable.

Code availability Not applicable.

Ethics approval Not applicable.

Consent to participate Not applicable.

Consent for publication Not applicable.

Authors' contributions Not applicable. 


\section{References}

[1] Aurich JC, Reichenbach IG, Schüler GM. Manufacture and application of ultra-small micro end mills. CIRP Ann - Manuf Techn 2012; 61(1): 83-86. doi:10.1016/j.cirp.2012.03.012.

[2] Atif M, Munish KG, Tadeusz M, Yurievich PD, Khaled G. Effect of tool coating and cutting parameters on surface roughness and burr formation during micromilling of Inconel 718. Metals 2021; 11(1): 1-18. doi:10.3390/MET11010167.

[3] Milan B, Andrea DB, Ekrem O, Alborz S, Dirk B. Experimental and computational investigations on the effects of deep-temperature emulsion on the turning of Inconel 718 alloy. CIRP J Manufacturin Sci Tec 2020; 31: 48-60. doi:10.1016/j.cirpj.2020.10.001.

[4] Wang W, Kweon SH, Yang SH. A study on roughness of the micro-end-milled surface produced by a miniatured machine tool. J Mater Process Tech 2005; 162-163: 702-708. doi:10.1016/j.jmatprotec.2005.02.141.

[5] Lu XH, Jia ZY, Wang H, Feng YX, Liang SY. The effect of cutting parameters on micro-hardness and the prediction of Vickers hardness based on a response surface methodology for micro-milling Inconel 718. Measurement 2019; 140: 56-62. doi:10.1016/j.measurement.2019.03.037.

[6] Mian AJ, Driver N, Mativenga PT. Identification of factors that dominate size effect in micro-machining. Int J Mach Tool Manu 2011; 51(5): 383-394. doi:10.1016/j.jjmachtools.2011.01.004. [7] Oliveira DD, Gomes MC, Silva MB. Influence of cutting fluid application frequency on the surface quality of micromilled slots on Inconel 718 alloy. Procedia Manuf 2020; 48: 553-558. doi:10.1016/j.promfg.2020.05.082.

[8] Ucun İ, Aslantaş K, Bedir F. The effect of minimum quantity lubrication and cryogenic pre-cooling on cutting performance in the micro milling of Inconel 718. P I Mech Eng B-J Eng 2015; 229(12): 2134-2143. doi:10.1177/0954405414546144.

[9] Evgeny B, Hughes T, Eskin D. Effect of surface roughness on corrosion behaviour of low carbon steel in inhibited $4 \mathrm{M}$ hydrochloric acid under laminar and turbulent flow conditions. Corros Sci 2016; 103: 196-205. doi:10.1016/j.corsci.2015.11.019.

[10] Alvarez RB, Martin HJ, Horstemeyer MF, Chandler MQ, Williams N, Wang PT, et al. Corrosion relationships as a function of time and surface roughness on a structural AE44 magnesium alloy. Corros Sci 2010; 52(5): 1635-1648. doi:10.1016/j.corsci.2010.01.018.

[11] Uddin MS, Rosman H, Hall C, Murphy P. Enhancing the corrosion resistance of biodegradable 
Mg-based alloy by machining-induced surface integrity: influence of machining parameters on surface roughness and hardness. Int J Adv Manuf Tech 2017; 90(5-8): 5095-5108. doi:10.1007/s00170-016-9536-X.

[12] Shen XH, Zhang JH, Yin TJ, Dong CJ. A study on cutting force in micro end milling with ultrasonic vibration. Adv Mater $\quad$ Res 2010; 905(198): 1910-1914. doi:10.4028/www.scientific.net/AMR.97-101.1910.

[13] Shen XH, Wang MY. Finite element analysis of temperature field in vibration milling. Key Eng Mater 2016; 693: 1030-1037. doi:10.4028/www.scientific.net/KEM.693.1030.

[14] Shen XH, Zhang JH, Li H, Wang JJ, Wang XC. Ultrasonic vibration-assisted milling of aluminum alloy. Int J Adv Manuf Tech 2012; 63(1-4): 41-49. doi:10.1007/s00170-011-3882-5.

[15] Chen G, Ren CZ, Zou YH, Qin XD, Lu LP, Li SP. Mechanism for material removal in ultrasonic vibration helical milling of Ti6Al4V alloy. Int J Mach Tool Manu 2019; 138: 1-13. doi:10.1016/j.ijmachtools.2018.11.001.

[16] Ni CB, Zhu LD, Yang ZC. Comparative investigation of tool wear mechanism and corresponding machined surface characterization in feed-direction ultrasonic vibration assisted milling of Ti-6Al-4V from dynamic view. Wear 2019; 436-437: 1-17. doi:10.1016/j.wear.2019.203006.

[17] Gong H, Fang FZ, Hu XT. Kinematic view of tool life in rotary ultrasonic side milling of hard and brittle materials. Int J Mach Tool Manu 2009; 50(3): 303-307. doi:10.1016/j.ijmachtools.2009.12.006. [18] Sajjady SA, Abadi HN, Amini S, Nosouhi R. Analytical and experimental study of topography of surface texture in ultrasonic vibration assisted turning. Mater Design 2016; 93: 311-23. doi:10.1016/j.matdes.2015.12.119.

[19] Tao GC, Ma C, Bai LY, Shen XH, Zhang JH. Feed-direction ultrasonic vibration-assisted milling surface texture formation. Mater Manuf Process 2017; 32(2): 193-198. doi:10.1080/10426914.2016.1198029.

[20] Zhang ML, Zhang DY, Geng DX, Shao ZY, Liu YH, Jiang XG. Effects of tool vibration on surface integrity in rotary ultrasonic elliptical end milling of Ti-6Al-4V. J Alloy Compd 2019; 821: 1-10. doi:10.1016/j.jallcom.2019.153266.

[21] Biermann D, Kersting P, Surmann T. A general approach to simulating workpiece vibrations during five-axis milling of turbine blades. CIRP Ann - Manuf Techn 2010; 59(1): 125-128. doi:10.1016/j.cirp.2010.03.057. 
[22] Lu H, Zhu LD, Yang ZC, Yan BL, Hao YP, Qin SQ. Research on the generation mechanism and interference of surface texture in ultrasonic vibration assisted milling. Int J Mech Sci 2021; 208: 1-18. doi:10.1016/J.IJMECSCI.2021.106681.

[23] Hsu CY, Huang CK, Wu CY. Milling of MAR-M247 nickel-based superalloy with high temperature and ultrasonic aiding. Int $\mathbf{J}$ Adv Manuf Tech 2007; 34(9-10): 857-866. doi:10.1007/s00170-006-0657-5.

[24] Suárez A, Veiga F, Lacalle LN, Polvorosa R, Lutze S, Wretland A. Effects of ultrasonics-assisted face milling on surface integrity and fatigue life of Ni-Alloy 718. J Mater Eng Perform 2016; 25(11): 5076-5086. doi:10.1007/s11665-016-2343-6.

[25] Wang Z, Kovvuri V, Araujo A, Bacci M, Hung WN, Bukkapatnam ST. Built-up-edge effects on surface deterioration in micromilling processes. J Manuf Process 2016; 24: 321-327. doi:10.1016/j.jmapro.2016.03.016.

[26] Thiele JD, Melkote SN. Effect of cutting edge geometry and workpiece hardness on surface generation in the finish hard turning of AISI 52100 steel. J Mater Process Tech 1999; 94: 216-226. doi:10.1016/S0924-0136(99)00111-9.

[27] Liu HT, Sun YZ, Geng YQ, Shan DB. Experimental research of milling force and surface quality for TC4 titanium alloy of micro-milling. Int $\mathrm{J}$ Adv Manuf Tech 2015; 79(1-4): 705-716. doi:10.1007/s00170-015-6844-5.

[28] Zhu LD, Ni CB, Yang ZC, Liu CF. Investigations of micro-textured surface generation mechanism and tribological properties in ultrasonic vibration-assisted milling of Ti-6Al-4V. Precis Eng 2019; 57: 229-243. doi:10.1016/j.precisioneng.2019.04.010.

[29] Cheng YN, Xu M, Guan R, Liu L, Qian J. Generation mechanism of insert residual stress while cutting 508III steel. Int J Adv Manuf Tech 2017; 91(1-4): 247-255. doi:10.1007/s00170-016-9724-8.

[30] Saoubi RM, Outeiro JC, Chandrasekaran H, Dillon Jr OW, Jawahir IS. A review of surface integrity in machining and its impact on functional performance and life of machined products. Int $\mathbf{J}$ Sus Manuf 2008; 1(1-2): 203-236. doi:10.1504/IJSM.2008.019234.

[31] Zuo Y, Wang HT, Xiong JP. The aspect ratio of surface grooves and metastable pitting of stainless steel. Corros Sci 2002; 44(1): 25-35. doi:10.1016/S0010-938X(01)00039-7.

[32] Huang J, Li Z, Liaw B Y, Zhang JB. Graphical analysis of electrochemical impedance spectroscopy data in Bode and Nyquist representations. J Power Sources 2016; 309: 82-98. 
doi:10.1016/j.jpowsour.2016.01.073. 